\title{
A Methodology to Assess the Safety of Aircraft Operations When Aerodrome Obstacle Standards Cannot Be Met*
}

\author{
Hartmut Fricke ${ }^{1}$, Christoph Thiel ${ }^{2}$ \\ ${ }^{1}$ Dresden University of Technology, Chair of Air Transport Technology and Logistics, Dresden, Germany \\ ${ }^{2} \mathrm{GfL}-$ Gesellschaft für Luftverkehrsforschung, Dresden, Germany \\ Email: fricke@ifl.tu-dresden.de, thiel@gfl-consult.de
}

Received 9 February 2015; accepted 20 February 2015; published 27 February 2015

Copyright (C) 2015 by authors and Scientific Research Publishing Inc.

This work is licensed under the Creative Commons Attribution International License (CC BY).

http://creativecommons.org/licenses/by/4.0/

(c) (i) Open Access

\begin{abstract}
When Aerodrome Obstacle Standards cannot be met as a result of urban or technical development, an aeronautical study can be carried out with the permission of EASA, in conjunction with ICAO, to prove how aircrafts can achieve an equivalent level of safety. However currently, no detailed guidance for this procedure exists. This paper proposes such a safety assessment methodology in order to value obstacle clearance violations around airports. This method has already been applied to a safety case at Frankfurt Airport where a tower elevating $4 \mathrm{~km}$ out of threshold 25R severely violates obstacle limitation surfaces. The model data refers to a take-off and landing performance model (TLPM) computing precisely aircraft trajectories for both standard and engine out conditions at ground proximity. The generated tracks are used to estimate collision risk incrementally considering EASA/FAA, EU-OPS \& ICAO clearance criteria. Normal operations are assessed with a probabilistic analysis of empirical take-off/landing track data generating the local actual navigation performance (ANP) on site. The ANP shows integration to collision risk for an aircraft with any obstacle. The obstacle is tested for clearance within a "5-step-plan" against all performance requirements for landing climb and take-off climb. The methodology thereby delivers a comprehensive risk picture: The presented safety case for Frankfurt Airport showed an equivalent safety level despite the violation of standards. The collision risk during both normal and degraded performance operations was still found to be within ICAO Collision Risk Model (CRM) limits, requiring only limited risk mitigation measures. The presented work should complement ICAO Doc 9774 Appendix 3.
\end{abstract}

\section{Keywords}

Aeronautical Study, Aircraft Performance, Obstacle Clearance, Collision Risk,

*An application to a Large Close-in Obstacle at Frankfurt Airport’s New Runway System. 


\section{Engine out Operations}

\section{Introduction to Obstacle Clearance}

Today's obstacle clearance criteria according to ICAO Annex 14 [1], PANS OPS Doc 8168 [2], recently came into European law through the EASA CS ADR DSN [3], which still refers to the 50 years old collision risk model (CRM). Meanwhile, aircraft (navigation) performance has significantly improved [4] [5], thereby often making today's obstacle clearance requirements too conservative. Estates around airports have become scarce, valuable resources for industry suffering from over-conservative clearance requirements. Large airport projects such as new runways at Frankfurt, Vienna, Berlin or Munich airports demonstrate the potential conflict between urban planning and air traffic operators' interests. From a scientific standpoint, existing regulations for departure/arrival procedure design, obstacle clearance evaluation and collision risk determination do not show congruent requirements with two target levels of safety (TLS) values in place: The CRM TLS [6] is valid for the precision approach segment ending at OCA/H (which is often far above the obstacle hot spots around airports) and the A-SMGCS TLS [7] is valid during ground taxi only. A systematic approach specifically detailing the evaluation of non-compliant obstacles through an aeronautical study as depicted in ICAO Doc 9774 Appendix 3 [8] is therefore crucial for making the best use of land around airports without hampering the safe operation of aircrafts. Also this approach should bring transparency into the various safety margin concepts and be incorporated in the above standards.

This paper recalls existing guiding material for assessing the compliance of obstacles with clearance requirements in Section 2, summarizes the analysis processes for valuing obstacles against these requirements in Section 3, and presents a model built to assess the non-conformant obstacle induced collision risk for departing and landing aircrafts while also bridging the various clearance considerations under normal and critically degraded performance conditions facing mechanical and operational flight aspects in Section 4 (engine out, crosswind etc.). This paper also collects the findings of a safety case in Frankfurt Airport which was successfully investigated with the presented approach in Section 5. Section 6 closes with a vision on how the presented concept may complement ICAO/EASA recommended practices to foster a transparent, formalized assessment of non-compliant obstacles in the complex airport environment.

\section{Obstacle Clearance Determination}

Obstacle clearance is of relevance for runway design according to ICAO Annex 14 [1], and Doc ADM [9], for procedure design (ICAO Doc 8168 PANS OPS) [2], aircraft operation (EU-OPS) [10], and aircraft certification (EASA CS 25 [11], FAR Part 25 Large Aeroplanes [12]). All these different requirements lead to given height margins above the ground respective of any obstacle (in fact vertical safety margins). They implicitly dictate a level of safety to avoid the risk of aircraft collision either with a ground plane or other obstacle. However, all three subjects refer to different geometric design standards and aircraft conditions. A safety model of Aircraft Operations when Aerodrome Obstacle Standards cannot be met therefore has to consider all three subjects and decipher any discrepancies and then build either transfer functions or determine the most stringent, limiting case. They are recalled briefly in the next subsections.

\subsection{Obstacle Limitation Surfaces at Runway Design}

A comprehensive set of standards and recommended practices has been internationally established based on ICAO Annex 14 and Doc 8168. Centered on each take-off/landing Runway, the ANC Obstacle Clearance Panel (OPC) defined limitation surfaces as early as 1976 and is intended to protect aircrafts in flight at ground proximity (see Figure 1).

The design of these horizontal and inclined surfaces obviously follows aircraft performance aspects (e.g. reference angle of climb/descent after take-off/during final approach) by adding safety margins to the design path. An e.g. 5.2\% (equals $3.0^{\circ}$ ) design angle of descent during final approach is enveloped by the approach surface with a slope of $2.0 \%$ ( $1^{\text {st }}$ section) to $2.5 \%$ ( $2^{\text {nd }}$ section) inclination for a precision runway CAT I Code 3, 4 (Annex 14; Table 4-1, ch 4-8 [1]). Similarly, the take-off climb surface for a Code 3, 4 take-off runway inclines with $2.0 \%$; again inducing safety margins as aircrafts typically climb with a gradient of $5 \%$ to $8 \%$. To conclude, the 
OLS grant a certain, however unspecified maximum collision risk for aircraft providing a given navigation performance (ANP) operating on that runway. The following Figure 2 shows the current obstacle collision risk during a conventional ILS approach based on realistic ANP values [5]. It further highlights the gradients of ICAO's obstacle clearance surfaces OLS and OAS (which apply to precision approaches only).

As we assume regardless of the chosen approach procedure of an equal safety target level, the difference in altitude for both dotted lines can only be considered in addition to the "safety margin" necessary for operations with lower ANP e.g. for non-precision approaches (NPA), which will be the subject of the following Section 2.2.

\subsection{Obstacle Clearance Applied during Procedure Design}

Closely connected to runway design, procedure design covers the detailed three-dimensional construction of approach and departure procedures to and from an instrument runway. For e.g. Code 3, 4 precision instrument runways, usually a large set of alternative procedures have been developed to fulfill environmental (noise

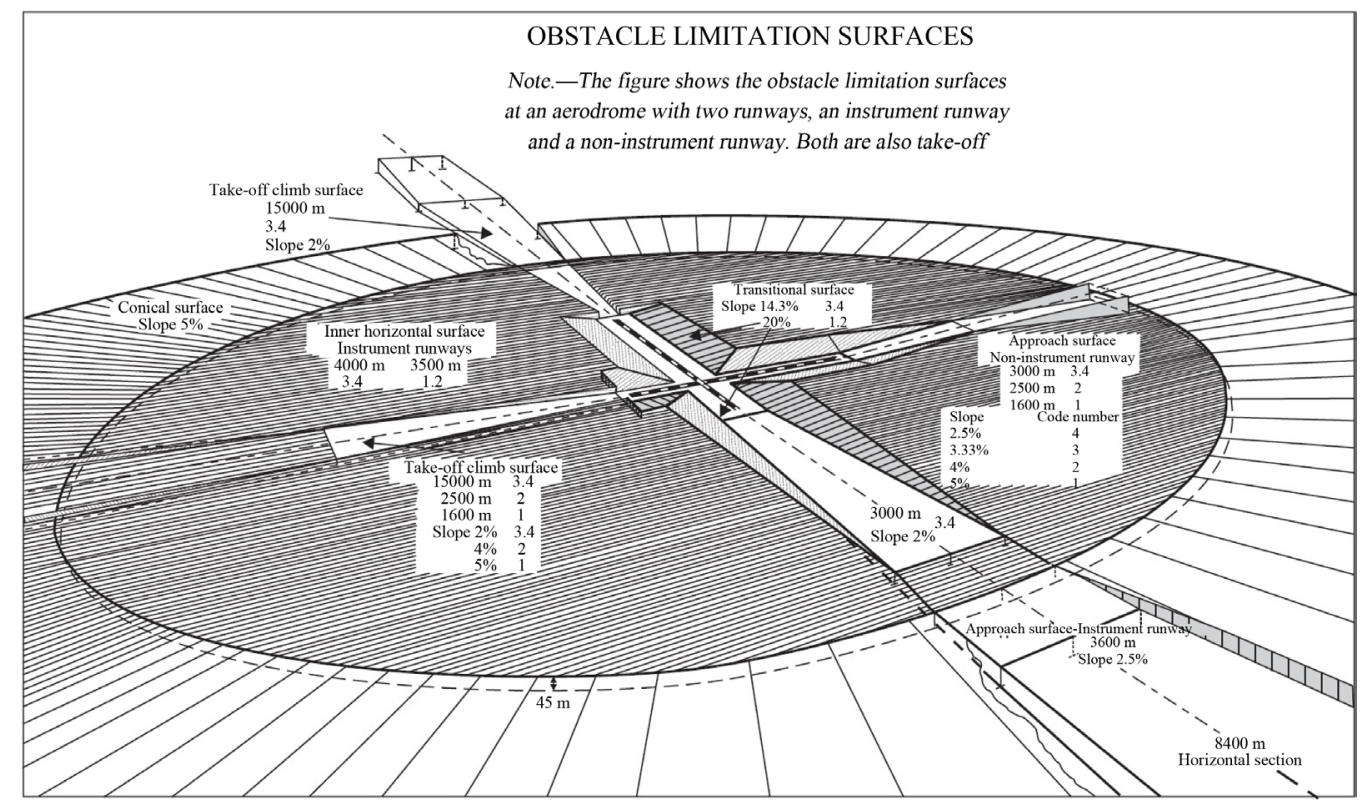

Figure 1. Obstacle limitation surfaces, Annex 14, Att. B; p. 313 [1].

\section{Comparison of OLS, OAS vertical profiles and flown trajectories (ANP)}

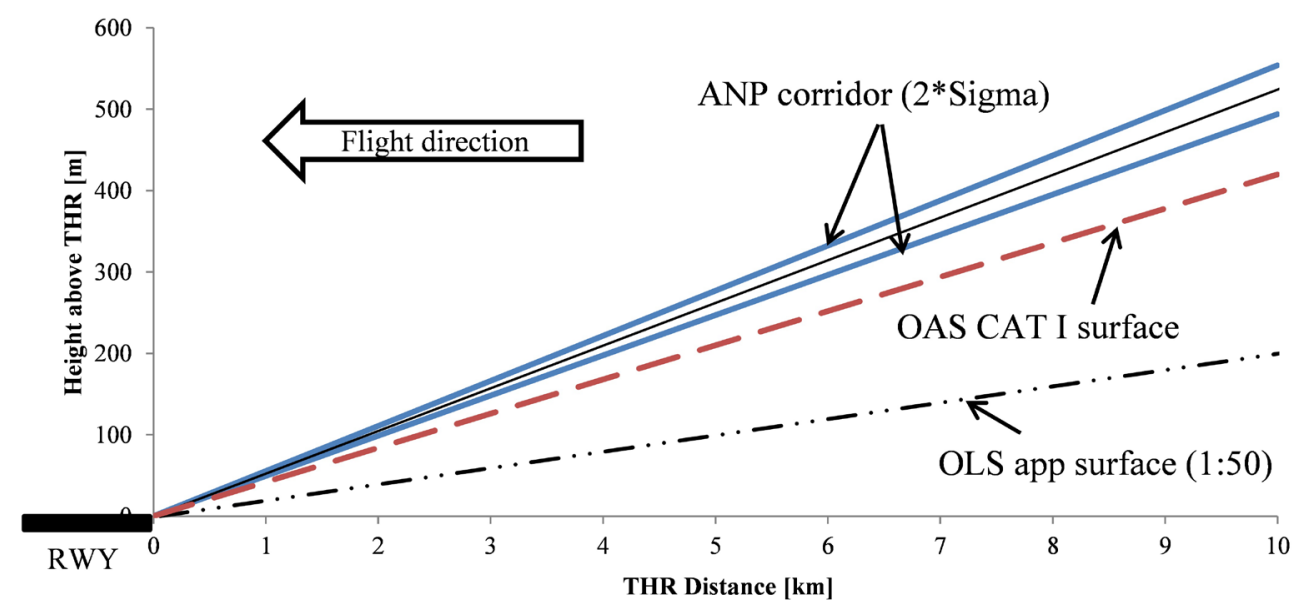

Figure 2. Heterogeneous safety margins resulting from OLS and OAS (during approach). 
abatement), operational (direct routings), safety aspects (e.g. non precision approaches offered as contingency procedures), as well as to consider geographically dispersed in- and outbound traffic flows.

With regard to precision or APV approaches, ICAO Doc 8168 [2] dictates the consideration of Obstacle Assessment Surfaces (OAS) consisting of inclined surfaces referenced to the threshold of that runway. They look similar to the OLS with a less conservative character (see Figure 2) but extending into the missed approach (not shown): Two alternative safety conclusions can be drawn when comparing OLS versus OAS: Either the OLS allows lower ANP to also methodologically cover NPA (as derived in Section 2.1) with the OAS laying above the OLS, or a different level of obstacle collision risk is implicitly accepted. Consequently, safety assessment will have to include all obstacle related procedure surfaces extending to the visual (approach) segment surface (VSS), the outbound obstacle identification surface (OIS) and the on-following take-off funnel. The VSS prolongs the OAS from the Obstacle Clearance Altitude/Height (OCA/H) down to the ground plane, assuming there is only visual guidance capability for the cockpit crew leading to lower ANP. As the OCA/H itself is also specific for each procedure and depends on the obstacle situation, the whole design process has potential for closed loop configurations (obstacle drives OCA/H and so the length of the VSS). So we can conclude that the OAS, different from the OLS, is not only representing significantly differing CR values but also allowing for two different design concepts: Either it determines those obstacles to be considered in the calculation of the associated OCA/H to the procedure ${ }^{1}$ or once set, refuses further adoptions induced by new obstacles by just interpreting OAS as obstacle limitation surface (which de facto is often the case). The ICAO Collision Risk Model (CRM) [6] as introduced in the 70s, however, does not cover the testing of these different design options; it only considers the OAS as an approximated $10^{-7}$ per operation collision iso-risk line neglecting time and PA procedure specific aircraft ANP figures. The presented assessment will also have to overcome this (second) deficiency.

For departures (see Figure 3), consideration includes, beside the OLS, the OIS extending from the DER with a 2.5\% inclination, which is meant to be compared to the Procedure Design Gradient (PDG) for each procedure. To know the local CR and considering all such identified obstacles, ideally we have to refer to the local ANP for each specific procedure during both normal and also "abnormal" conditions. Abnormal conditions assume one engine inoperative (OEI) conditions and so cover rare but safety critical occurrences along the risk estimation.

\section{Comparison of OLS vertical profile and flown trajectories} (ANP)

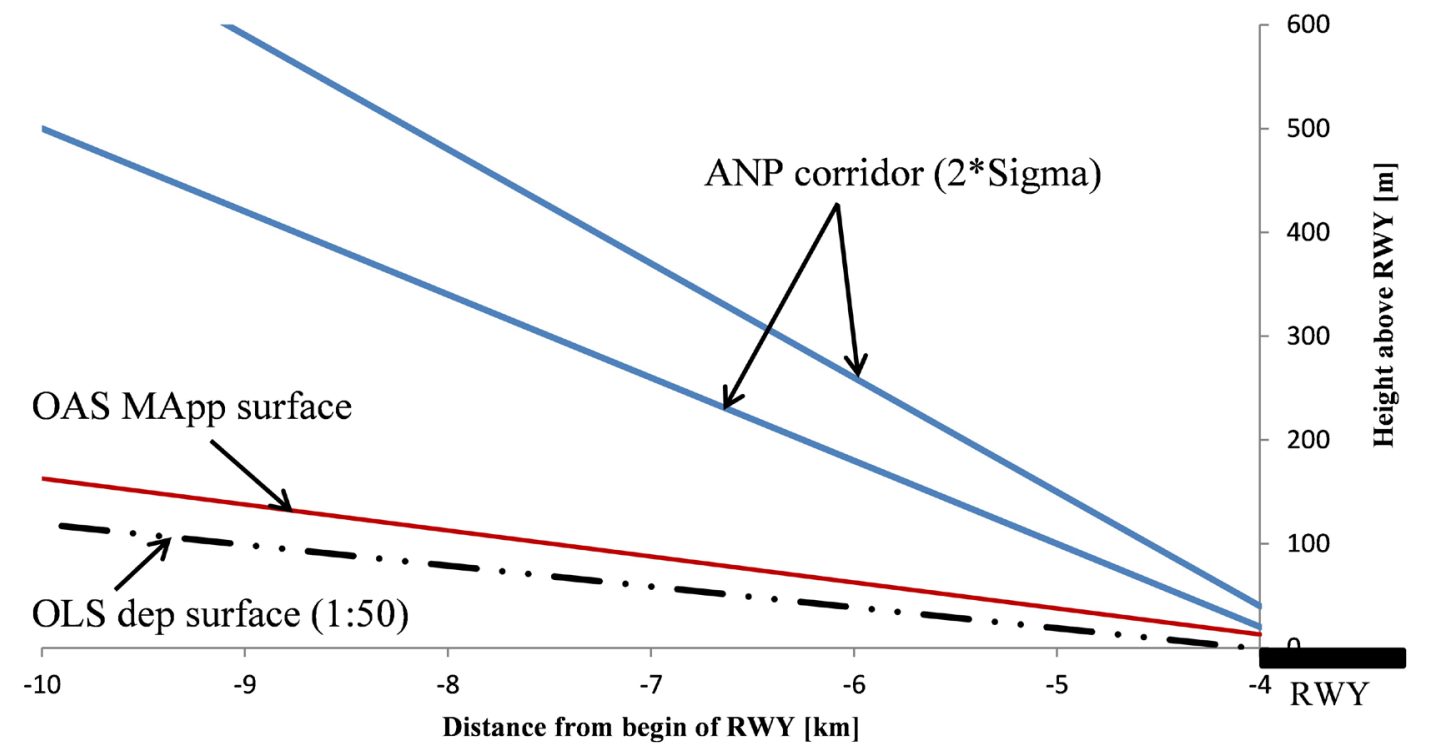

Figure 3. Heterogeneous safety margins resulting from OLS and OAS (departure).

${ }^{1}$ Obstacle clearance altitude is referenced to mean sea level and obstacle clearance height is referenced to the threshold elevation or in the case of non-precision approaches to the aerodrome elevation or the threshold elevation. ICAO Doc 8168, Vol. II, Section I-1-1-6 [2]. Beyond the OCA/H, the approach surface is extended by a Visual Approach Surface (VSS) assuming the reduced aircraft ANP as guidance is formally limited to visual cues. 


\subsection{Aircraft Certification}

The various surfaces (OLS, OAS, VSS, and OIS) analyses all assume that aircraft operate at normal performance conditions. Certification of aircraft according to FAA Part 25 [12] resp. EASA referring to CS-25 [11], however, takes additionally degraded, OEI performance test cases during take-off, final approach and landing climb into consideration. The aircraft, therefore, must be accelerated on the ground to the engine failure speed $v_{\mathrm{EF}}$, at which point the critical OEI condition begins, lasting for the rest of the take-off (EASA CS-25.109/ CS25.111 ff. [11]). The take-off section ends, the climb phase begins at $35 \mathrm{ft}$. (jet aircraft, $50 \mathrm{ft}$. prop aircraft) above the take-off surface at the end of the take-off distance ( $15 \mathrm{ft}$. for wet runways). From there on, the aircraft must demonstrate its climb performance as a so-called gross flight path which will be diminished by aircraft type specific climb gradient reductions, which generate yet another safety margin: e.g. $0.8 \%$ for two-engine aircrafts along the take-off flight path. So far there is no evidence for the correlation of the safety impact to that of the regulatory requirement. A comprehensive safety assessment will also have to tackle this (third) aspect.

To conclude, all certified aircrafts must demonstrate their certified required take-off, landing distances and climb out performance. A second branch of test cases for obstacle clearance will have to be considered aside those tackled in the first and second bunch of clearance considerations like degraded aircraft performance combined with unfavorable ambient conditions like crosswind. These effects can best be handled by defining hazard scenarios in which the aircraft must prove obstacle clearance in terms of e.g. demonstrating minimum climb performance.

The following Sections 3 and 4 present the concept for a Safety Assessment (SA) aiming at satisfying all of the above requirements; thusly bridging the different requirements coming from airport planning, procedure planning and the certification of aircrafts. In so doing, we hope to generate a transparent and homogeneous risk picture.

\section{Analysis of Non-Compliant Obstacles}

When conducting the SA, we start with systematically spotting obstacles in the vicinity of the runway system as candidates for violating one of the clearance criteria as presented in Section 2. This process is not executed obstacle by obstacle but by limitation criteria starting from the most stringent to the least with reference to Figure 2 and Figure 3. Respectively, the following process forms the hazard assessment phase of the SA.

\subsection{Approach and Take-Off OLS Investigations}

Independent from specific aircraft performance criteria, EASA generally requires OLS considerations as follows: "OLS means a series of surfaces that define the limits to which objects may project into the airspace around aerodrome to be ideally maintained free from obstacles” [3]. Of course, we can convert these surfaces into performance criteria and thereby determine the implicit climb/descent requirement:

$$
\begin{gathered}
\tan \gamma=1 / 50=0.02 \text { (OLS dep/arr surface gradient) } \\
\gamma_{\text {OLS }}=1.145^{\circ}
\end{gathered}
$$

Regardless of any obstacle clearance considerations, we can calculate the minimum climb gradient and minimum rate of climb (and descent) ROC/ROD as follows for the given low altitude and small climb angles:

$$
\mathrm{ROC} / \mathrm{ROD}_{\text {minOLS }}=\mathrm{TASsin} \gamma_{\text {minoLs }} \approx \mathrm{CAS} \gamma_{\text {minoLs }}
$$

For a typical final approach $\left(v_{\mathrm{REF}}\right)$ resp. climb out safety calibrated airspeed $\left(v_{2}\right)$ of $150 \mathrm{kt}$, this leads to a $\mathrm{ROC} / \mathrm{ROD}_{\text {minoLs }}=300 \mathrm{ft} . / \mathrm{min}$, proving a very conservative safety character of the OLS surfaces, equaling very low safety requirements as is shown in Section 4.

\subsection{Approach and Missed Approach OAS Investigations}

As shown in Figure 2 for a given ANP distribution along the flight track, the OAS are less conservative than the OLS; however, they do not equally consider specific aircraft performance categories but solely the PA category, localizer location and further system related parameters. For keeping those surfaces free of obstacles, the following vertical flight path requirements for a typical ILS, CAT I, 3 glideslope OAS result: 


$$
\begin{gathered}
\gamma_{\text {App OAS }}=-1.62^{\circ} \\
\gamma_{\text {MissedApp OAS }}=1.43^{\circ}
\end{gathered}
$$

Which leads with (3) to:

$$
\begin{gathered}
\mathrm{ROD}_{\text {App }}=430 \mathrm{ft} . / \mathrm{min} \\
\mathrm{ROC}_{\text {MissedApp }}=380 \mathrm{ft} . / \mathrm{min}
\end{gathered}
$$

The higher gradient values in Equations (4) and (5) show the usefulness of the chosen process. It should, however, be noticed that in few cases for very close-in obstacles the OAS may formally be more restrictive than the OLS. Still in those few cases the OLS prevails (PANS-OPS Volume II Part III Attachment B [2]).

\subsection{The Role of the Obstacle Clearance Altitude}

The final instrument approach ends and the missed approach segment begins at the OCA/H. The higher the value, the earlier the pilot needs visual contact to the runway to continue landing. Non-precision approaches with $\mathrm{OCH} \geq 600 \mathrm{ft}$. suffer limited usability due to insufficient visibility and ceiling for the sake of safety. With regard to CR, we may further notice that the OCA/H induces far more conservative safety margins than for PA with up to $250 \mathrm{ft}$. clearance for close-in obstacles in the primary area compared to $35 \mathrm{ft}$. for take-off (see above). The OCA/H as third test case gains further complexity as it must be calculated for each (stall speed related) aircraft category [13]. Finally, we may further take into consideration when obstacles are typically closer to the runway then where the OCA/H is being reached; this test case is sequenced at third position.

\subsection{Net Flight Take-Off Path Analysis}

During type and aircraft specific certification, the aircraft now has to demonstrate landing climb, take-off and climb out performance under both normal and degraded conditions. This demonstrated performance will potentially limit its operational capabilities in terms of maximum allowable masses, payload, and range. E.g. if a given climb gradient or a declared distance cannot be met, take-off mass (as fuel or traffic load) must be reduced and will limit profitability of the flight. This process is driven by the parameter weight $(W)$, required thrust $(T)$, power $(P)$ and selected climb out safety speed $\left(v_{2}\right)$, as those trigger climb performance as shown in Equation (3). $T$ and $v_{2}$ are coupled at constant speed through:

$$
\begin{gathered}
T=\frac{\mathrm{d} m_{\text {Air }}+\mathrm{d} m_{\text {Fuel }}}{\mathrm{d} t} v_{\mathrm{EG}}-\frac{\mathrm{d} m_{\text {Air }}}{\mathrm{d} t} v_{2}-K \quad \text { and } \quad \sin \gamma=\frac{T-D}{W} \\
P=T * v_{2} \quad \text { and } \quad v_{2} * \sin \gamma=\mathrm{ROC}=v_{2}\left(\frac{T-D}{W}\right)
\end{gathered}
$$

$\mathrm{EG}=$ exhaust gas, $K=$ pressure effect forces, $D=$ drag

Equation (8) shows the linear correlation of climb gradient (CG) and weight, Equation (9) the respective linearity between operating speed and ROC/ROD. Along the take-off flight path, the " $2^{\text {nd }}$ segment" implies the highest CG. Obstacles must be overflown with $35 \mathrm{ft}$. clearance. As climb-out profiles are more inclined, obstacle limitations likely become more limiting in the approach and landing phase. Independently, we again can determine a minimum clearance requirement resulting from a procedure design similar to the process in Section 3.1 . With the procedure design gradient (PDG) [2] at 3.3\% (OIS gradient of $2.5 \%$ plus $0.8 \%$ safety margin) we equally can calculate a rate of climb (ROC) for a given climb out speed $v_{2}$ :

$$
\gamma_{\text {Dep }}=1.89^{\circ}
$$

$$
\text { with } v_{2}=150 \mathrm{kt} \text { we come to } \mathrm{ROC}_{\text {Dep }}=500 \mathrm{ft} . / \mathrm{min}
$$

The slightly higher ROC values in (11) compared to (7) imply to rank this test to this subsequent position. Figure 4 depicts the additional safety margin versus Figure 2 and Figure 3 resulting from the $35 \mathrm{ft}$. clearance requirement which reduces the CR provided in the same ANP value and distribution (shown in Figure 4 as 


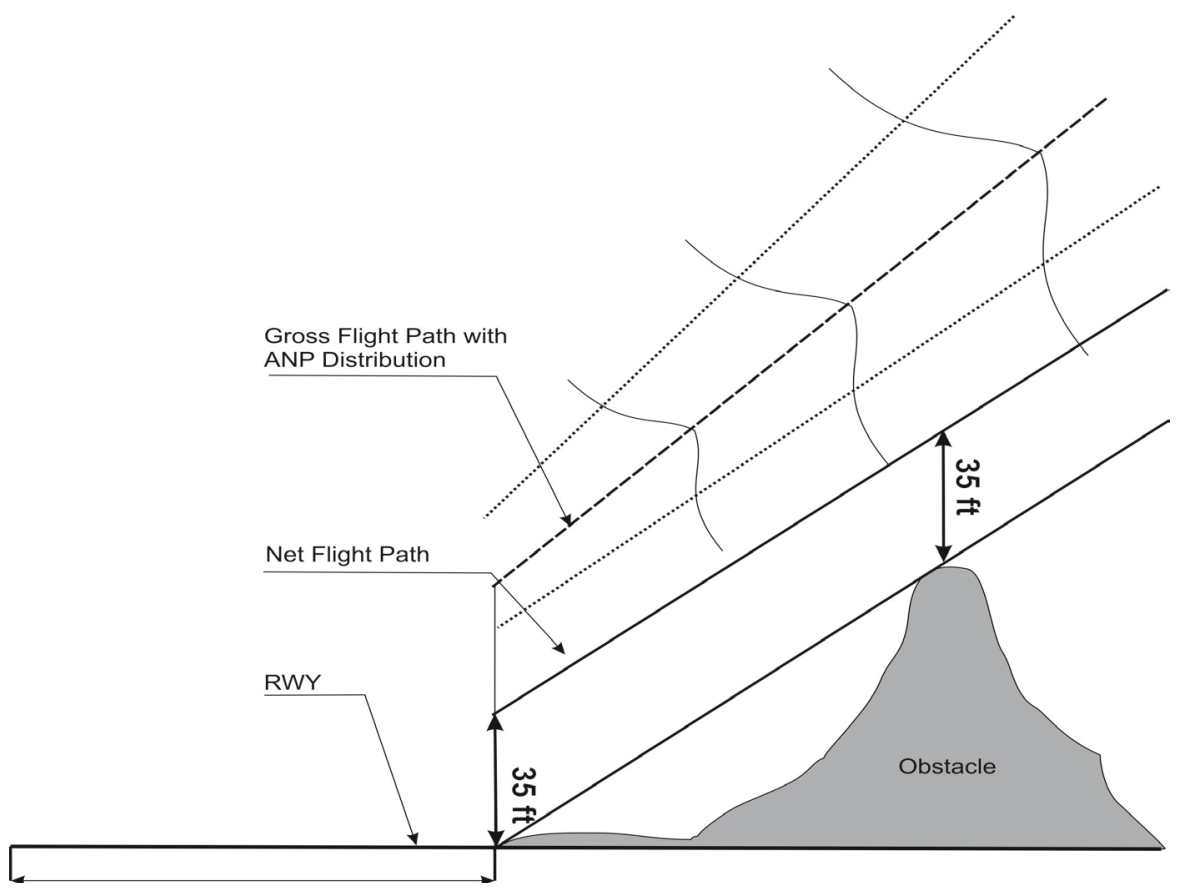

Figure 4. Additional obstacle clearance and required net flight path corrections resulting in lower CR as for OLS and OAS.

sketch).

With today's economic pressure in the ATM System, limitations for take-off mass are hardly acceptable especially at large (Code 3,4 ) airports. As such, the safety test case will usually be performed with maximum structural take-off and respective landing mass considerations.

It shall be noticed that this fourth step also demonstrates some complexity; however, it does not considercompared to step three-detailed stall speed dependent aircraft categories but a simplified threefold concept only relying on the number of engines (2, 3 or 4) installed. An obstacle therefore only becomes relevant if the respective CG requirements are not met leaving a $35 \mathrm{ft}$. clearance above the object. The clearance surface can so be represented by the inclined (net flight path) surface when reduced by $35 \mathrm{ft}$.

Section 4 incorporates this analysis concept and adds systematic algorithms to the presented analysis to form the SA.

\section{Safety Assessment Methodology}

\subsection{Legitimation}

A general philosophy of handling exceptions from the presented standards has been adopted by $\mathrm{ICAO}^{2}$ in Doc 9774 [8] and has recently been significantly relaxed by EASA in CS-ADR DSN [3]. Accordingly, a so-called Aeronautical Study can be applied as Acceptable Means of Compliance for certain violations such as obstacles conflicting with the large horizontal obstacle limitation surface. Explicitly, ICAO states "An aeronautical study is a study of an aeronautical problem to identify possible solutions and select a solution that is acceptable without degrading safety” [8]. As such, supervisory authorities in ICAO member states generally agree with ICAO non-compliant constellations or procedures as long as such study proves an equivalent safety level. However, there is no specific guideline given by the ICAO about how to conduct these safety assessments.

Therefore, the main goal of the presented methodology is to design a uniform concept for obstacle approval verification clearly having in mind the implicitly deferring safety margins as presented in Section 2.

\footnotetext{
"“New objects or extensions of existing objects should not be permitted above the conical surface and the inner horizontal surface... except when, in the opinion of the appropriate authority, an object would be shielded by an existing immovable object, or after aeronautical study it is determined that the object would not adversely affect the safety or significantly affect the regularity of operations of aeroplanes” [1].
} 


\subsection{Architecture}

In line with Eurocontrol's SAM [14], an Aeronautical Study shall comprise the following main sections: Hazard Assessment and Safety Risk Analysis, including potential risk mitigation. The main hazard to be assessed here is very simple: The collision with any formally non-compliant obstacle according to Section 3.

For the Safety Assessment Analysis, the chart in following Figure 5 has been built to comprehensively consider the (main) hazard with the findings of Section 2.

As shown, the model comprises of two main components: The analysis of normal operations and of quite rare but safety critical, degraded operational performance (emergency related operations). It so covers all potential flight scenarios related to the (main) hazard. For each of the next steps, the probability to divert from the desired flight path towards the obstacle is being determined and valued against the safety target in place according to Section 2.

Normal operations are flight procedures compliant with the standard operational procedures (SOP) as published for the specific aircraft and following the ATC clearances as filed and expected. As such, also a take-off with one engine inoperative is basically a normal operation, whereas the same take-off e.g. leaving the cleared departure route (SID) for unspecified reasons is considered an emergency operation. For safety considerations, emergency operations always assume a degraded aircraft performance behavior when assessing the effects to the declared hazard.

\subsubsection{Normal Operations}

Normal operations statistically represent more than $99 \%$ of all operations at large (Code 3, 4) airports. The Normal Operations model (NOM) processes historic aircraft track data from departures resp. arrivals at the investigated airport for a significant time period (typically six months) gathered from radar or multi-lateration sensors. Similar to the ICAO CRM methodology [6], the real track data will be compared to the defined track data and modeled as offset probability density functions (PDF). The PDF concept has also been adopted by ICAO with their RNAV/RNP or PBN documents [15].

We proved in [5] that for all studied cases, aircraft navigation performance behaves normally. Nonetheless, we allow the NOM to begin again, first only assuming two dimensional ( $y$ as cross track reference, $z$ as vertical reference) Gauss PDFs, $f(y), f(z)$ with a $2 \sigma$ value as procedure level of quality identifier (e.g. RNP 0.3 for a non-precision approach procedure equals a square root variance of $0.3 \mathrm{NM}$ left and right to the desired flight path for $95 \%$ of the flying time) [15]. This is analytically described at each location along the flight track as shown in Equation (3) for the cross track plane $y$ :

$$
f(y)=\frac{1}{\sigma_{y} \sqrt{2 \pi}} \mathrm{e}^{-\frac{\left(y-\mu_{y}\right)^{2}}{\sigma_{y}^{2}}}
$$

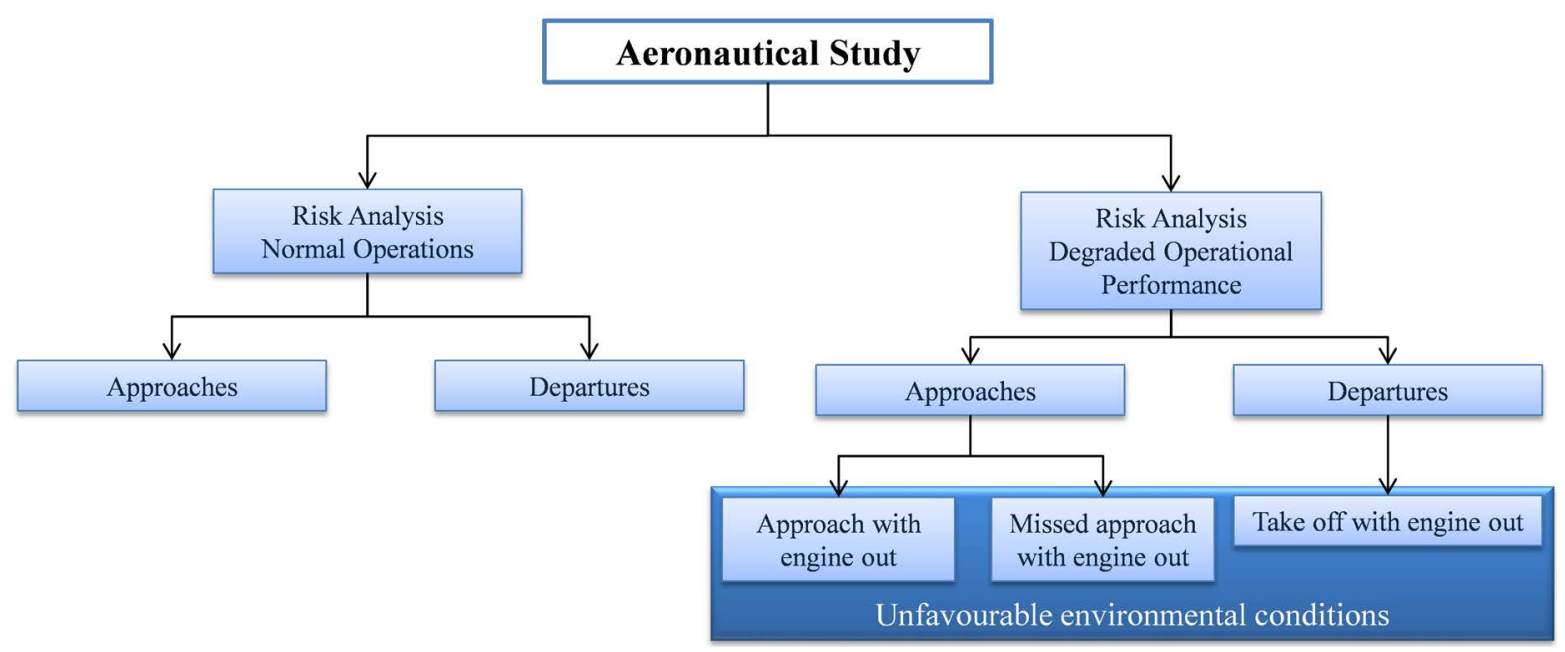

Figure 5. Model architecture of safety assessment methodology. 
So $y$ and $z$ represent the track coordinates as sampled, the mean with $\mu$ and its variance with $\sigma^{2}$. It shall be noticed that track considerations are unnecessary in the given context since CR is considered as time independent.

After verifying the assumption of normality of the track data by means of chi-squared tests along the flight track, a Grubbs' test is applied to detect potential outliers. Grubbs' test detects one outlier at a time. Each potential outlier is expunged from the dataset and the test is iterated until no (more) outliers are detected. Along the defined take-off or approach path, vertical cuts through the cross track plane provide insight into the shape characteristics. This methodology has already been effectively applied in [5]. Following the normal distribution, mean and standard deviation reflect the graphical center and height of each "bell" curve (see Figure 6).

The NOM systematically integrates the local PDF to a dedicated obstacle distance both vertical and lateral at the abeam location along the flight path to calculate the local collision risk (CR) for that object. The CR per movement can then be compared to a pre-set TLS such as the ICAO CRM TLS, as shown in the following Figure 7 for the lateral plane with different iso-risk contours $\left(1 \times 10^{-3}, 1 \times 10^{-5}, 1 \times 10^{-7}\right.$, and $\left.1 \times 10^{-10}\right)$.

By extending the integration boundaries accordingly, the $\mathrm{CR}$ can also be calculated against the ground plane or any height above ground to estimate a ground/height projected risk contour laterally enveloping the flight path. It may, however, be noticed that close to the ground, track data typically is remarkable unreliability due to radar beam refraction and multi path phenomena. This should be overcome by applying multi-sensor strategies such as additionally using multi-lateration track data. In conjunction with these sensor aspects, the NOM allows safety comparisons of any procedural obstacle clearance standard.

Accordingly, the following Table 1 collects the computed risk levels using ANP from [5] at a preselected height above ground for the OAS and OAS (CAT I) approach surfaces.

Table 1 clearly shows the different implicitly (ICAO) accepted CR if we start from identical ANP values. The target CR varies between $2.2 \times 10^{-32}$ and $2.2 \times 10^{-23}$ at a $3000 \mathrm{~m}$ distance from the runway location. This difference rises even higher for larger threshold (THR) distances. The NOM, therefore, proves to be crucial for generating a comprehensive obstacle clearance risk picture.

Of course, the ANP distribution may (slightly) vary depending on the (time dependent) environmental conditions or differing procedures, e.g. a conventional straight-in precision approach (PA) vs. a more innovative

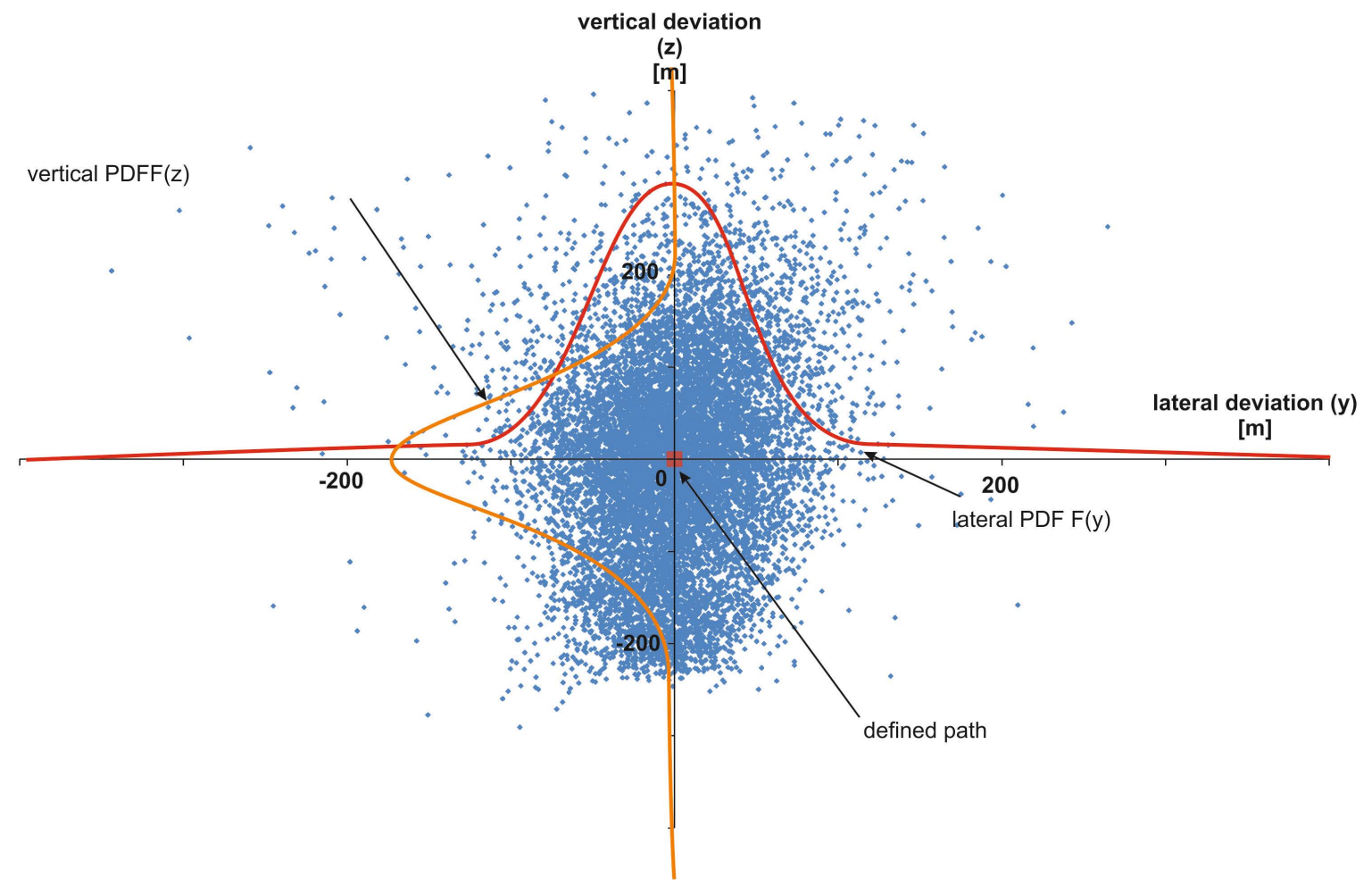

Figure 6. Normally distributed track offsets around the flight path. 


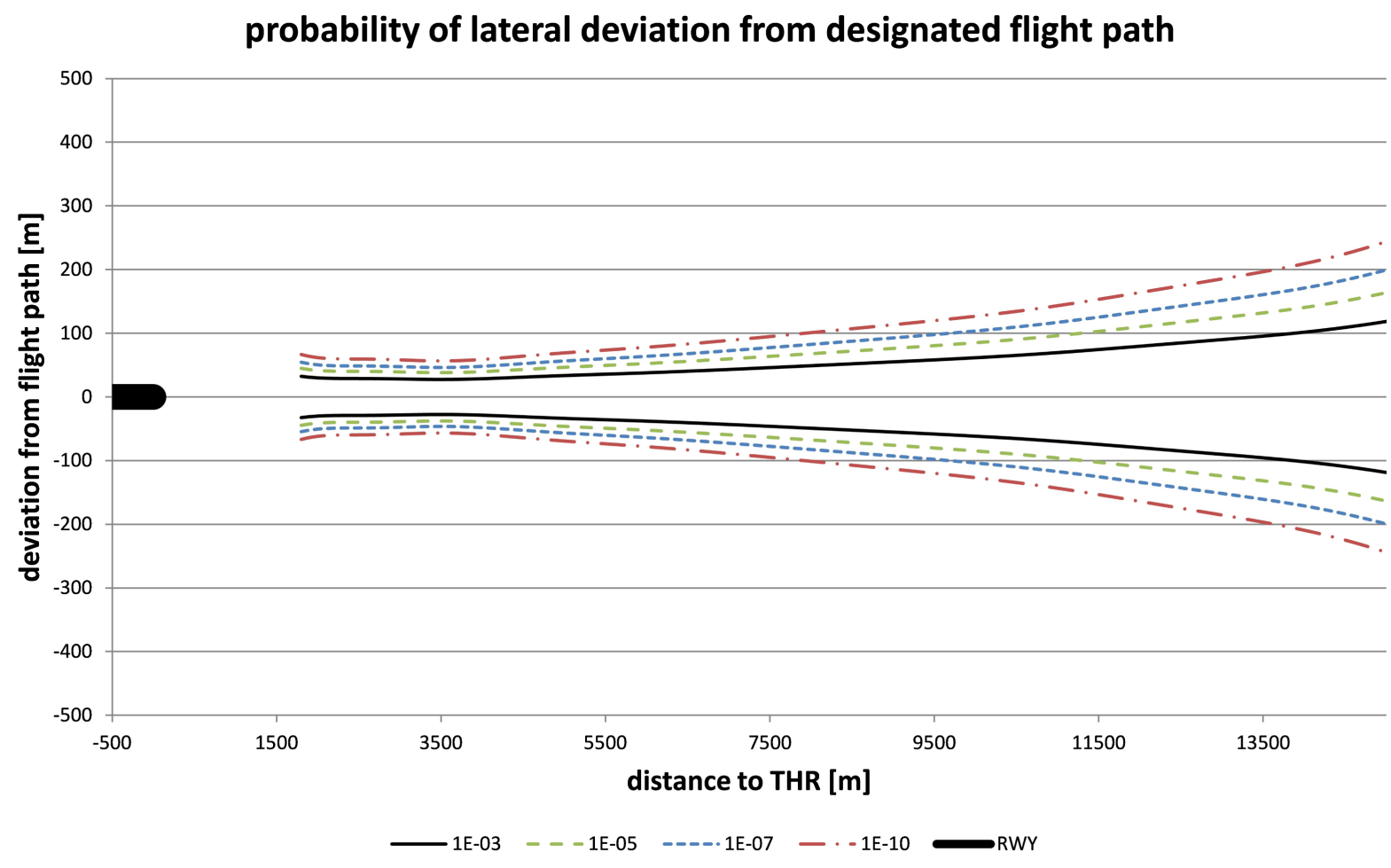

Figure 7. Probability of lateral deviation from designated flight path or risk to hit an obstacle with $C R(z)=1$ in lateral plane.

Table 1. Collision risks for different approach surfaces, related to $3^{\circ}$ glide path and ANP.

\begin{tabular}{|c|c|c|c|c|c|}
\hline \multirow{2}{*}{$\begin{array}{l}\text { Distance to } \\
\text { threshold [m] }\end{array}$} & \multirow{2}{*}{$\begin{array}{l}\text { Height of the } \\
3^{\circ} \mathrm{GP}\end{array}$} & \multicolumn{4}{|c|}{ Probability to undercut a defined surface } \\
\hline & & Calc. sigma vertical & Surface & Height of the surface & Calc. collision risk \\
\hline \multirow{2}{*}{1000} & \multirow{2}{*}{$67.6 \mathrm{~m}$} & \multirow{2}{*}{$7.4 \mathrm{~m}$} & OLS & $18.1 \mathrm{~m}$ & $1.8 \mathrm{E}-11$ \\
\hline & & & OAS (CATI) & $20.5 \mathrm{~m}$ & $8.3 \mathrm{E}-11$ \\
\hline \multirow{2}{*}{2000} & \multirow{2}{*}{$120.6 \mathrm{~m}$} & \multirow{2}{*}{$8.5 \mathrm{~m}$} & OLS & $38.8 \mathrm{~m}$ & $6.6 \mathrm{E}-22$ \\
\hline & & & OAS (CATI) & $49.0 \mathrm{~m}$ & $3.3 \mathrm{E}-17$ \\
\hline \multirow{2}{*}{3000} & \multirow{2}{*}{$172.5 \mathrm{~m}$} & \multirow{2}{*}{$9.6 \mathrm{~m}$} & OLS & $58.8 \mathrm{~m}$ & $2.2 \mathrm{E}-32$ \\
\hline & & & OAS (CATI) & $77.5 \mathrm{~m}$ & $3.4 \mathrm{E}-23$ \\
\hline
\end{tabular}

segmented non precision approach (NPA). However, such differing ANP distributions do not alter the general conclusions drawn here, as we prove in [16].

\subsubsection{Degraded Operational Performance}

The degraded operational performance model (DOM) considers those effects of the remaining less than $1 \%$ traffic operations, those emergency or unspecified conditions which do not follow normal procedures according to SOP. These rare instances show a significantly increased collision risk as a result of flying un-cleared procedures combined with engine failure-what we assume here to be in reference to our safety case for a degraded performance of the aircraft during take-off or landing climb. From a statistical perspective, the DOM looks specifically at the (far) tails of the normal distributions used in the NOM. These tails cover only a small percentage of all track data $(<0.3 \%$ for a 3 Sigma threshold), their functional approximation being remarkably unreliable. To overcome this weakness, the DOM reverts to a scenario technique representing these seldom cases on a functional level, allowing to deterministically analyze a collision potential ("will pass the obstacle or not").

Regardless of the technical, meteorological or human factors related to the causes leading to these scenarios, 
the DOM computes the effect of degraded performance while also assuming unfavorable operational conditions such as a strong cross wind coming windward with respect to the remaining operative engine(s). This constellation increases at max the required wind correction angle (WCA, see Figure 8), thus degrading the lateral/vertical aircraft navigation performance.

This model is applied to all three constellations while assuming the most critical engine out case a few seconds ahead of passing the non-compliant obstacle:

1) Approach with two different settings (flaps extended, gear up) and landing configuration (flaps high/full, gear down).

2) Missed Approach at FAF as default (see Figure 9).

3) Take-off (at $v_{\mathrm{EF}}$ as default) with two different flap/slat settings to weigh-in corresponding CG and ROC effects on obstacle clearance. It minimizes these effects according to the following generalized aerodynamic effects (see Figure 10).

The Take-off and Landing Performance Model (TLPM) which evolves from the EJPM [17] calculates the resulting 3D tracks for all DOM scenarios. Validation was also performed with licensed flight planning software [18].
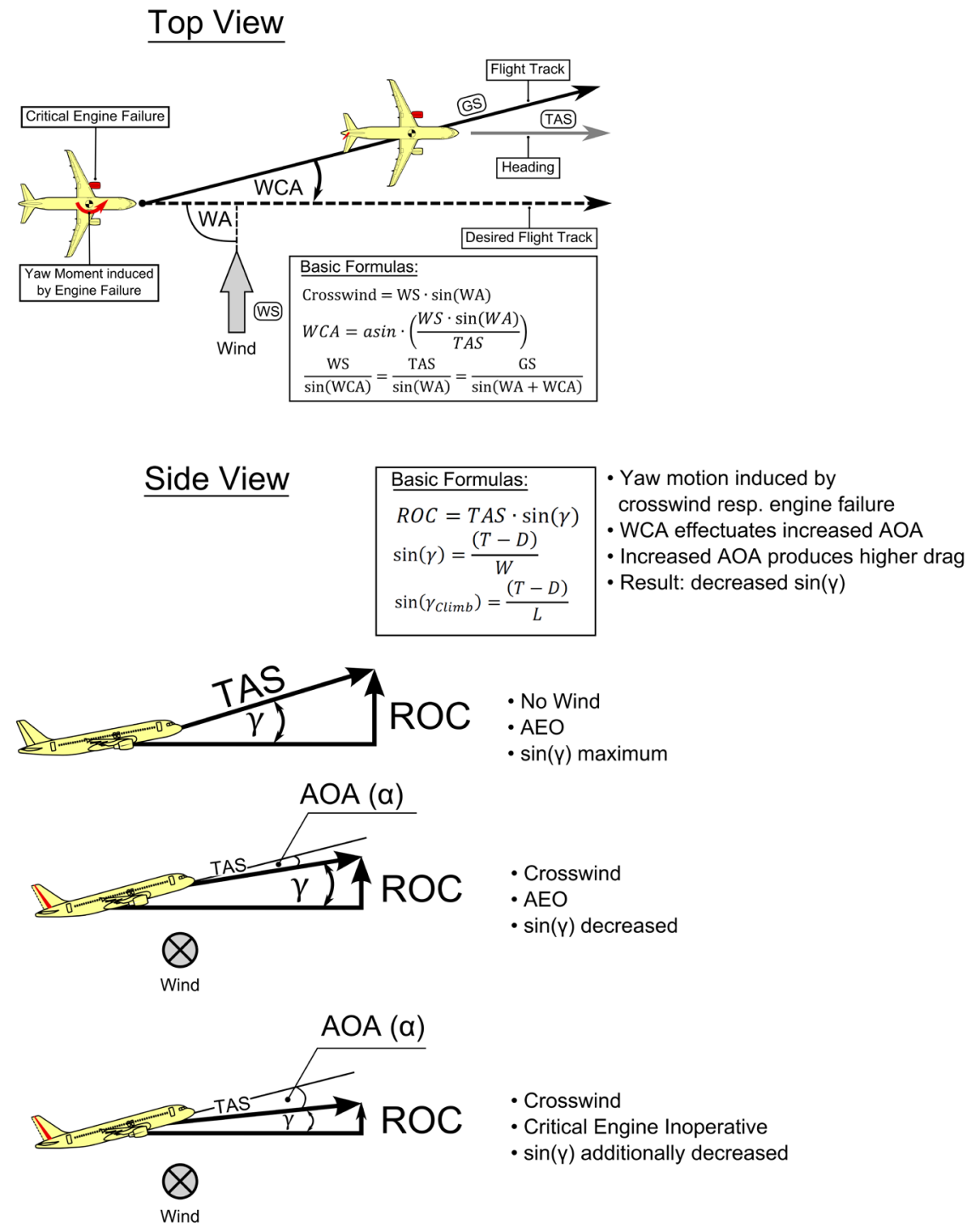

Figure 8. Underlying flight performance in the DOM. AOA = angle of attack, WA/WS = wind angle/speed, AEO = all engines operative. 

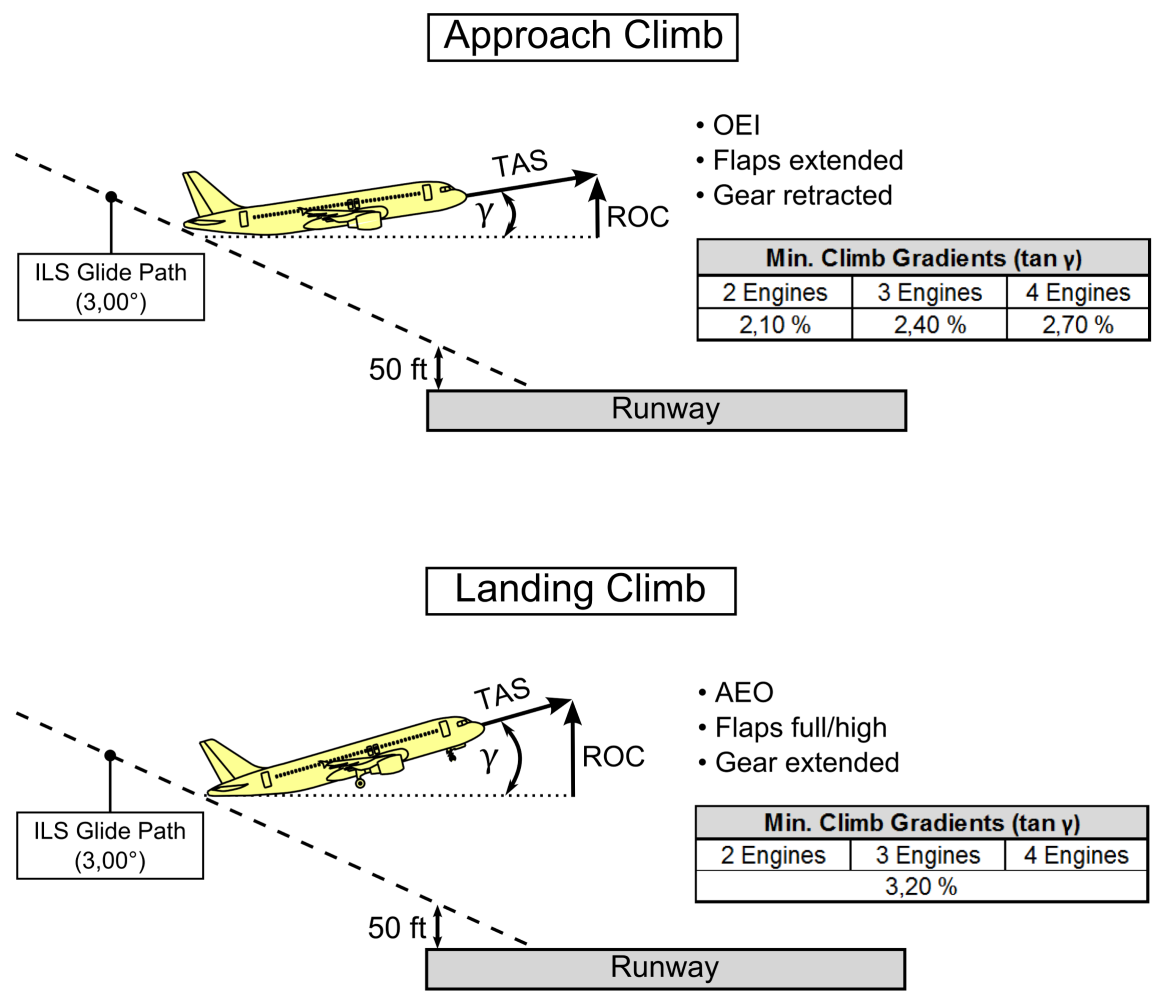

Figure 9. Worst case analysis for approach and landing climb obstacle clearance: Approach/landing configuration impact on ANP and rate of climb.
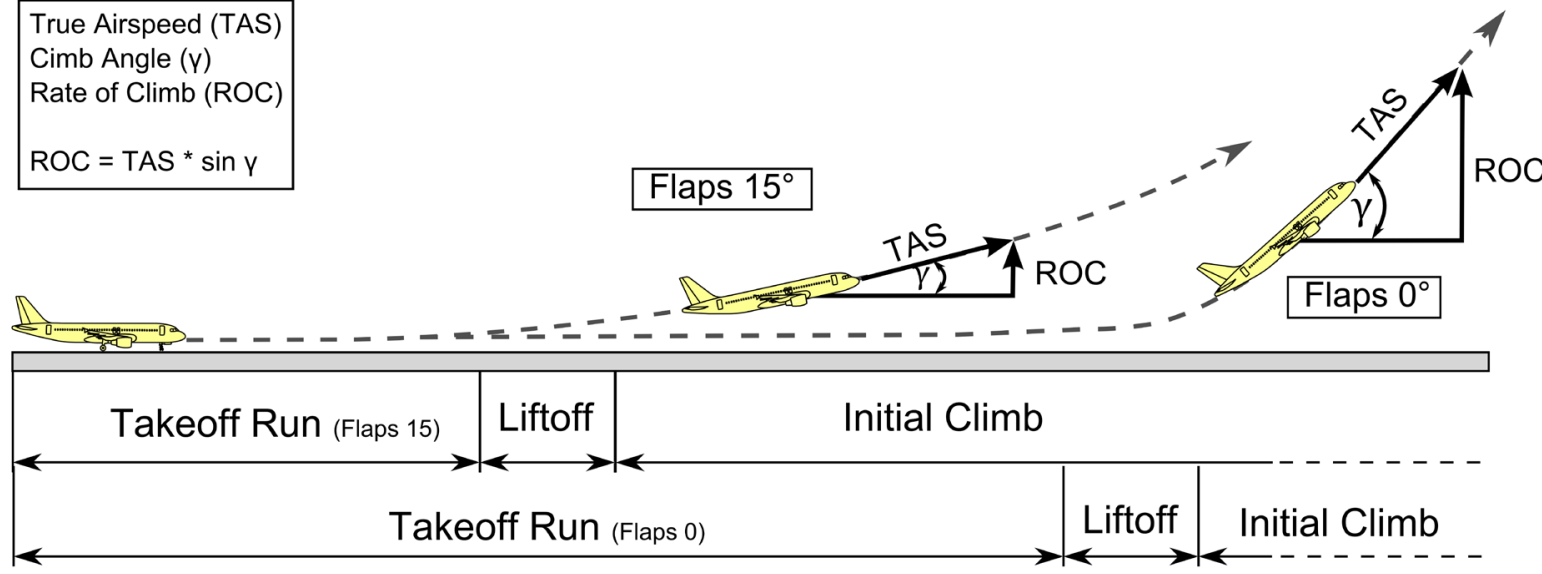

Figure 10. Lowest pass altitude analysis for take-off obstacle clearance.

The presented threefold flight performance analysis was embedded into a five-step evaluation scheme as follows:

DOM Step 1: Vertical Performance Analysis

Step 1 determines the vertical obstacle clearance by applying minimal vertical performance requirements according to EASA CS-25 for each scenario which contains the formulation of a "direct to" trajectory with the obstacle. It answers the following question.

"Based on purely vertical certification requirements: Do all aircrafts overfly the obstacle safely even if a direct trajectory towards the obstacle is assumed (regardless of the aircraft's capability to fly this horizontal trajectory)?”

For a positive result of all scenarios (the answer being yes), considering all aircraft performance types rele- 
vant to the airport, the DOM analysis is completed at step 1. Otherwise, we continue as follows (this is consecutively true for all on-following steps):

DOM Step 2: Procedure Design Analysis

Step 2 additionally contains lateral consideration of the obstacle with respect to all existing approach/departure procedures and their respective clearance requirements according to EU-OPS 1 [10] and ICAO PANS-OPS [2]. Therefore the question of step 2 is:

"Does the obstacle violate any departure or approach procedure clearance requirements?"

DOM Step 3: Lateral Performance Analysis

Additionally, step 3 considers, based on the trajectory resulting from step 1 (vertical) and step 2 (lateral), both additional lateral and vertical divergences from the intended route during approach or departure resulting from OEI and adverse wind assumption. Step 3 uses the TLPM to compute these critical trajectories to answer the question of step 3:

"Is the obstacle's location critical even if we assume OEI and adverse wind conditions?"

DOM Step 4: Lateral Flyability of the Critical Trajectory

Step 4 investigates the capability to fly that trajectory found to be most critical in step 3 through consideration of lateral performance aspects; e.g. maximum bank angle with flaps extended leading to limited turn radii. Step 4 answers the question:

"Is the developed, most critical trajectory flyable at all in terms of flight performance and flight mechanics?"

DOM Step 5: Vertical Performance Analysis of the Critical Trajectory

Step 5 investigates the aircraft's vertical flight profile as fixed in step 4 considering OEI yaw momentum induced drag. This one leads to generally degraded CG values (see also Figure 8). The question to be answered in this step can be concluded as follows:

"Are aircrafts flying the most critical trajectory possible in order to ensure sufficient flight altitude to cross the obstacle safely?”

Often step 5 concentrates on identifying aircraft classes with relatively poor climb performance (such as e.g. light twin engine prop aircraft or heavy aircraft such as A340).

With these five steps, the DOM thereby covers all effects resulting from adverse conditions resulting in a collision threat that is not yet covered by the NOM. This SA methodology was already applied for several safety cases in Germany. Section 5 reveals such application for demonstration and verification purposes.

\section{Safety Case Close-In Obstacle at Frankfurt Airport}

\subsection{Environmental Settings}

As stated in Section 4.2.1, the hazards, here the obstacle subject to investigation, need to be located relative to the runway system of Frankfurt Airport (FRA). We focus on an $80 \mathrm{~m}$ tower building located $600 \mathrm{~m}$ ahead of threshold 25C and $1100 \mathrm{~m}$ across its extended centerline, close-by the extended centerline of Frankfurt's new landing runway 25R (see Figure 11).

The obstacle clearance analysis with regard to the OLS of all relevant RWY directions proved a violation of the horizontal surface of the center RWY 25C/07C and of the south RWY 25L/07R. None of the OAS, however, was violated, as shown in following Figure 12.

\subsection{NOM Application}

Flight track data for a six month period at FRA was used for the ANP analysis preceding the CR calculations [19].

\subsubsection{Outbound Traffic Analysis}

All departure routes passing nearby the considered obstacle operating from runway 07C were analyzed (07R routes are farer away, 07L/25R allows landings only). As shown in Figure 13, flight tracks of the northbound departure route (SID) BIBTI 3E were identified as the most relevant ones.

The relevant cross section (the normal plane to the route through the obstacle) was found almost in the straight out segment of BIBTI 3E, at $600 \mathrm{~m}$ beyond DER. The route specific flight track's distribution are shown in Figure 14 at this cross section (BIBTI 3E in red, all other departures in blue). 


\section{Relative position of the obstacle}

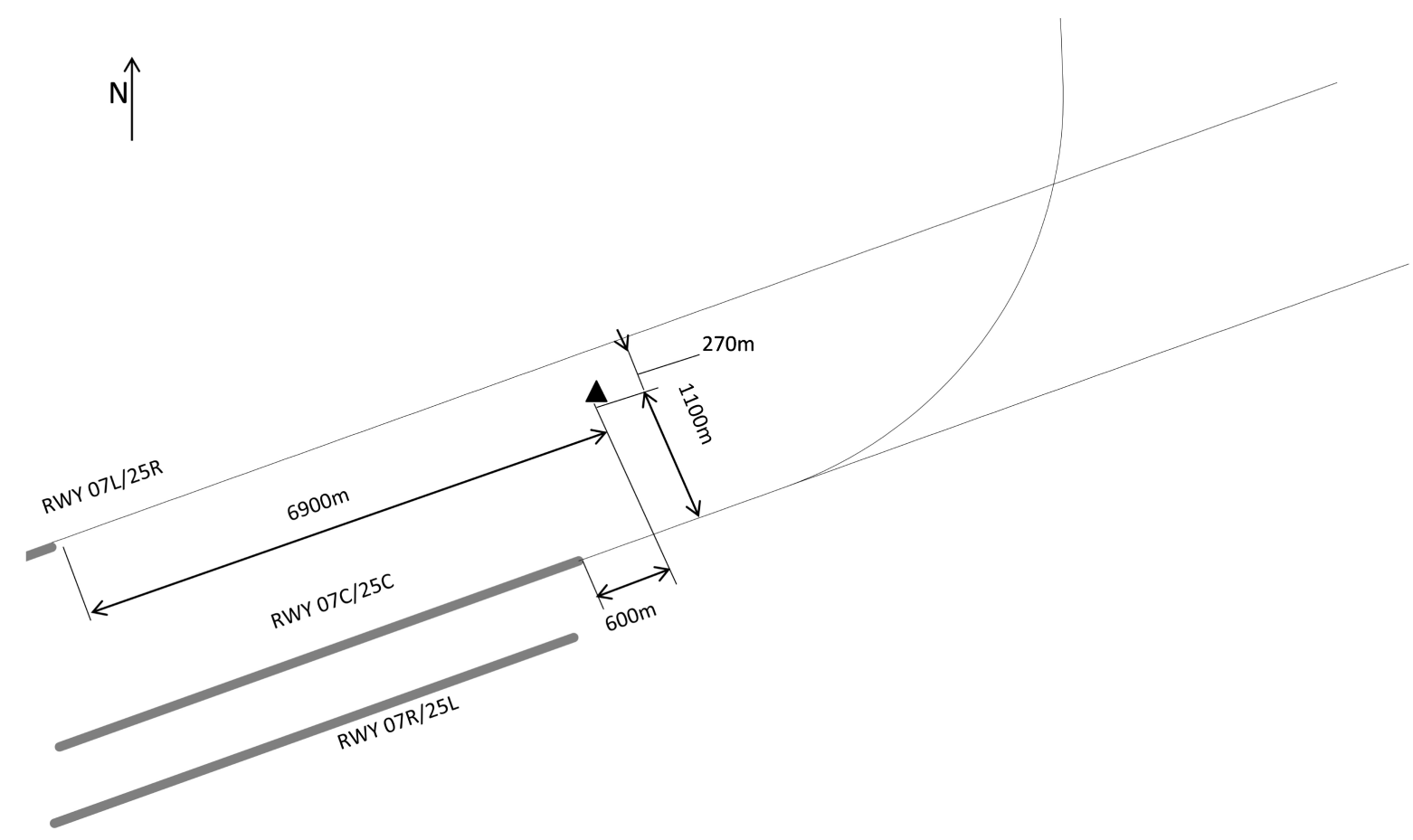

Figure 11. Location of the critical obstacle-the safety case EDDF.
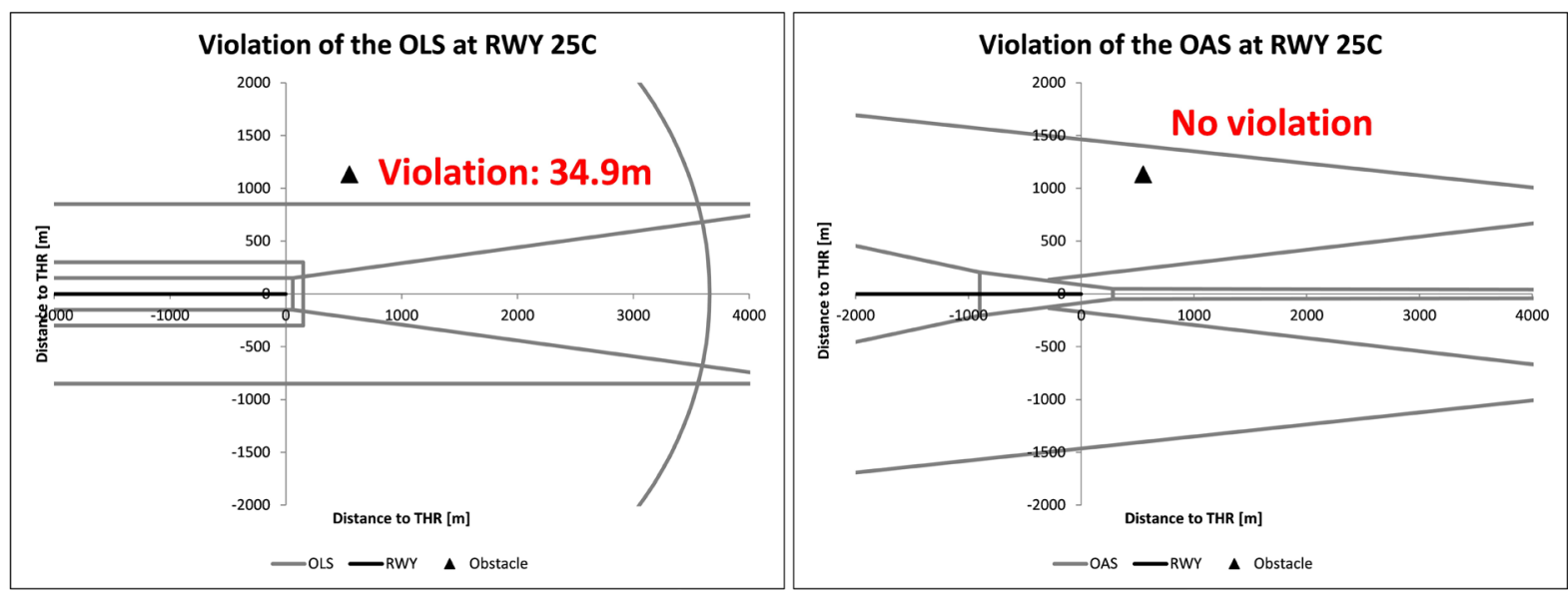

Figure 12. Excerpt of the obstacle clearance analysis for the runway 07/25C, OLS—left figure, OAS CAT I-right figure.

Figure 14 clearly shows a tendency for aircrafts on BIBTI 3E to climb faster than other traffic following a required PDG of 6.3\%. They also initiate the tendency of aircrafts to veer north (more located to the left in the figure) compared to the other traffic.

The SID specific ANP analyses were then performed along the statistical methods as explained in Section 3. Figure 15 shows the determined ANP values and resulting CR iso-risk lines for departing aircraft on BIBTI 3E and all other routes.

The poorest ANP values (XTT and VTT) per class of aircraft and per route are identified in Table 2. It also shows the probability density function's (PDF) parameter shape before/after the critical $600 \mathrm{~m}$ cross section.

The double integration of the PDF both vertically and laterally to the obstacle equals the specific CR per takeoff, as shown in following Table 3.

Due to the position of the obstacle at $600 \mathrm{~m}$ from DER, the CR VTT value is relatively high with $1.97 \times 10^{-2}$ 
Flight tracks to the north

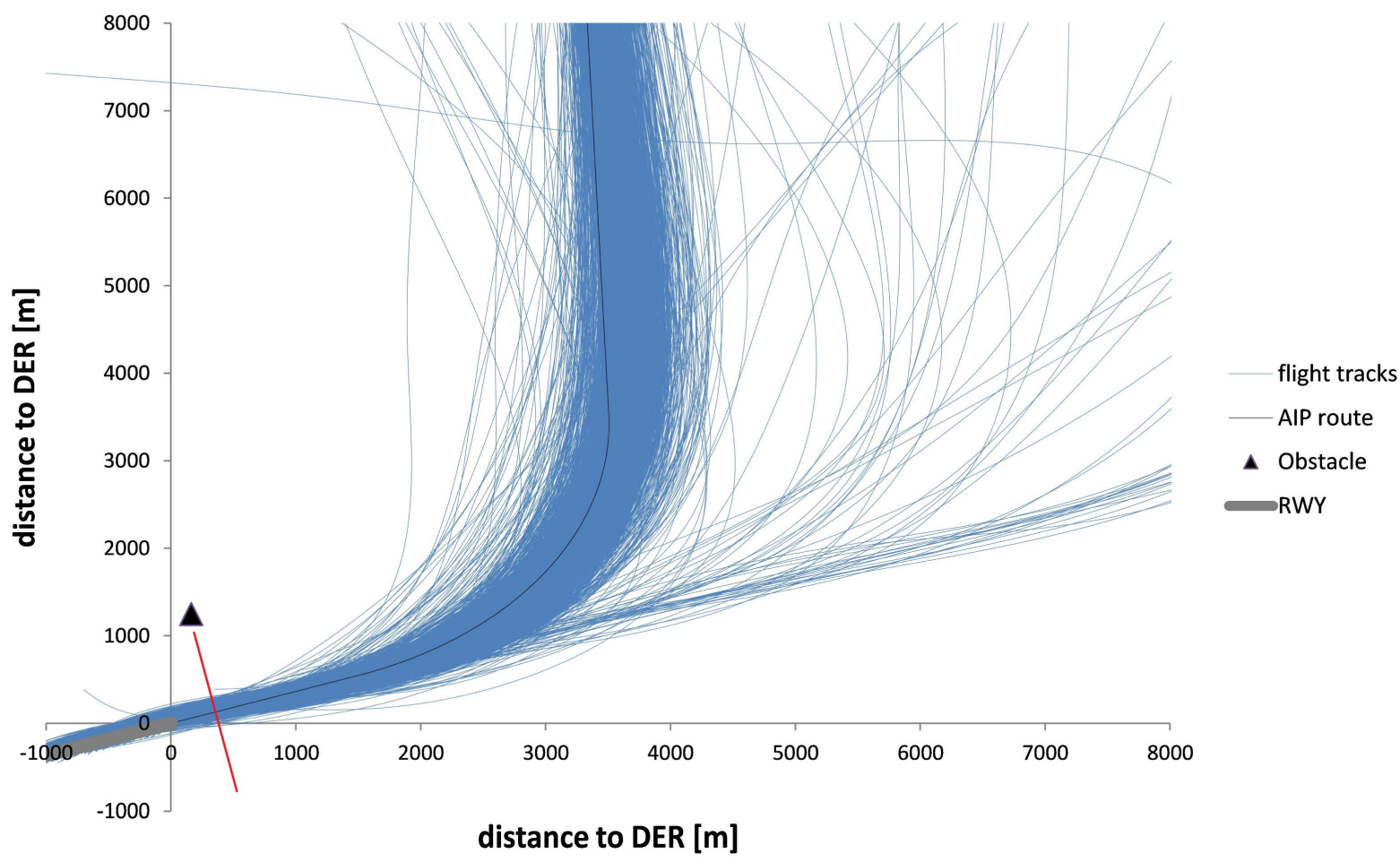

Figure 13. FRA Flight tracks for runways in use 07, outbound flights, FANOMOS Data, with obstacle critical cross section (red line).

\section{Cross Section at relevant distance $(600 \mathrm{~m}$ behind DER)}

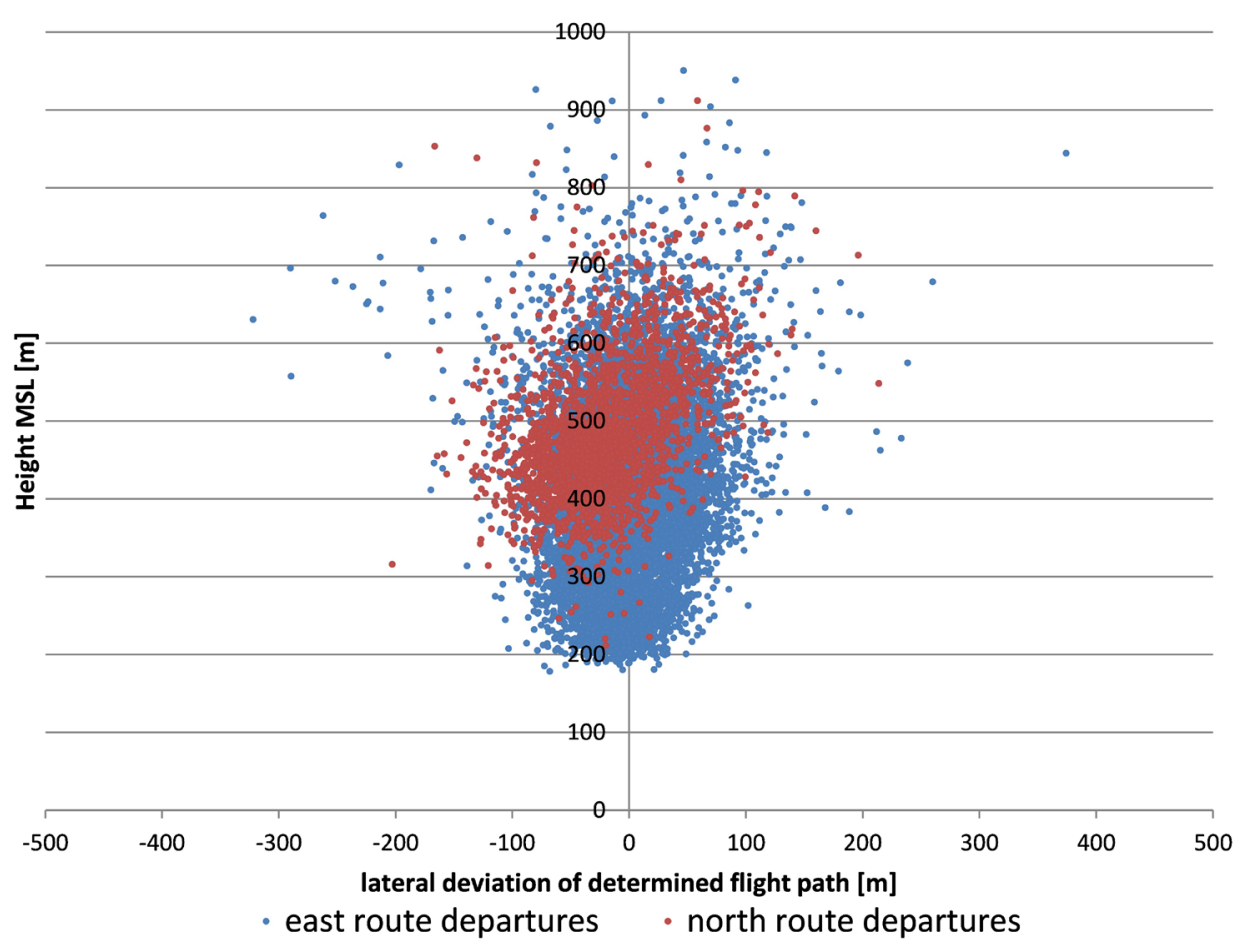

Figure 14. Relevant cross section passing through the critical obstacle at $600 \mathrm{~m}$ DER distance, departures from runway 07C. 


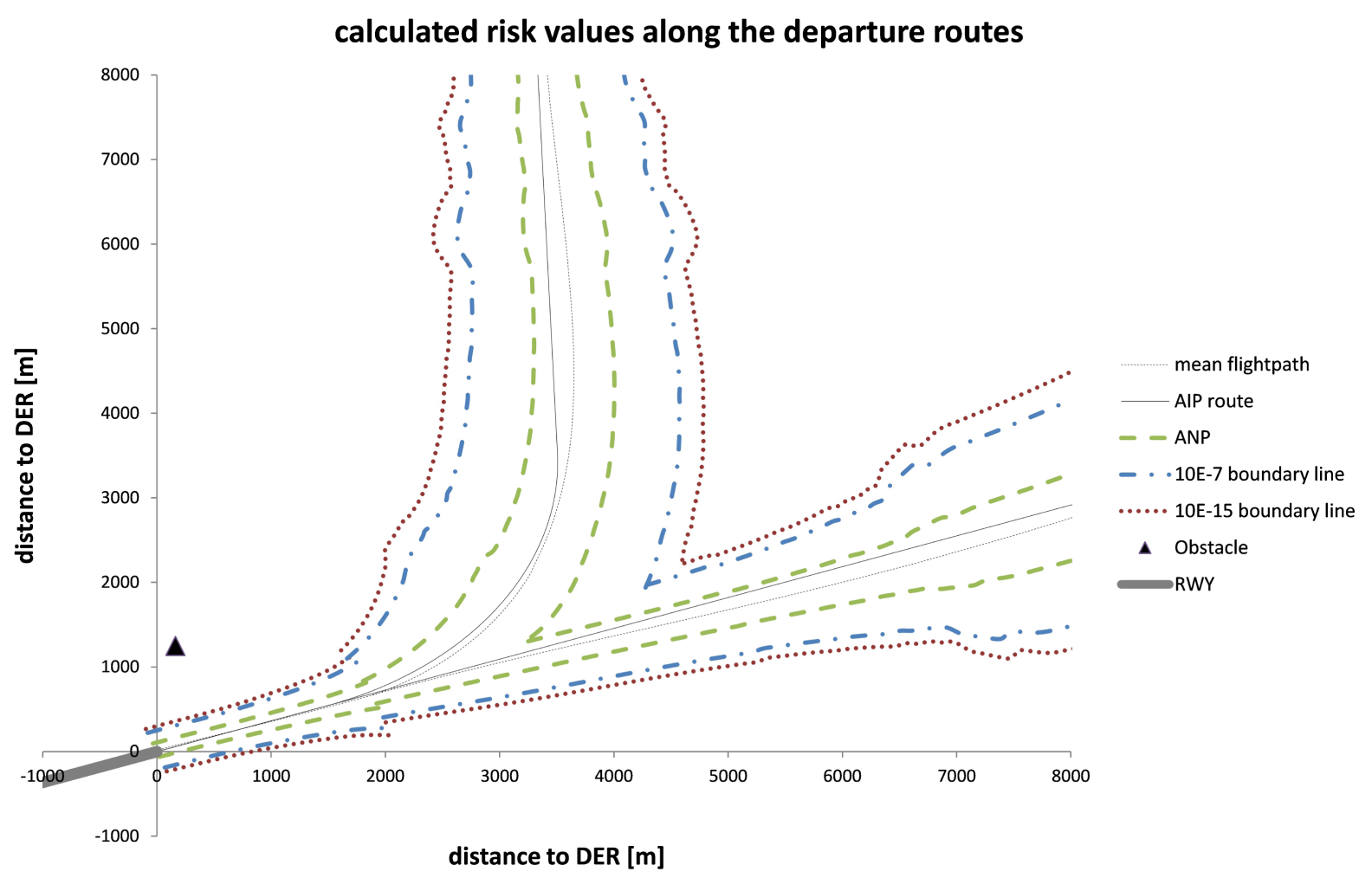

Figure 15. Iso-risk lines and ANP values, outbound flights on runway 07C.

Table 2. Statistical parameter along the flight track (critical cross section highlighted in gray).

\begin{tabular}{ccccc}
\hline \multirow{2}{*}{ Distance from DER [m] } & \multicolumn{2}{c}{ VERTICAL } & LATERAL \\
\cline { 2 - 5 } & Sigma [m] & VTT [NM] & Sigma [m] & XTT [NM] \\
\hline 400 & 85.0 & 0.092 & 43.5 & 0.047 \\
500 & 85.9 & 0.093 & 44.8 & 0.048 \\
600 & 86.6 & 0.094 & 45.7 & 0.049 \\
700 & 87.2 & 0.094 & 46.7 & 0.050 \\
800 & 87.9 & 0.095 & 47.7 & 0.051 \\
\hline
\end{tabular}

Table 3. Calculated collision risk for departures.

\begin{tabular}{ccc} 
& Collision risk & \\
\hline Lateral (XTT) & Vertical (VTT) & Per departure \\
\hline $2.10 \mathrm{E}-115$ & $1.97 \mathrm{E}-02$ & $4.13 \mathrm{E}-117$ \\
\hline
\end{tabular}

per departure; whereas the XTT related CR is-at a lateral offset of $1100 \mathrm{~m}$ for the obstacle from the route -negligible with values below $1 \times 10^{-100}$ per departure, result in an overall collision risk of $4.13 \times 10^{-117}$ per departure.

\subsubsection{Inbound Traffic Analysis}

For approaches, both north and center runway are relevant. Applying the same investigation steps as for the departures, we computed, compared to the outbound case, clearly higher ANP values as expected with $99 \%$ of all aircraft performing ILS approaches. This leads to respectively smaller CR figures below $1 \times 10^{-117}$. The calcu- 
lated CR via ICAO's CRM [6] showed as well a negligible CR outside the calculation limits of the CRM pro$\operatorname{gram}\left(<1 \times 10^{-15}\right.$ per approach).

We can thereby conclude that for the normal operations at Frankfurt Airport a collision risk for take-off and landing is below ICAO's TLS at $1 \times 10^{-7}$ per operation. The calculated CR below $1 \times 10^{-100}$ shows both the necessity for scenario based risk analyses, as provided with the DOM, and a further validation of ICAO's CRM.

\subsection{DOM Safety Case Application}

\subsubsection{Scenario Set-Up}

Based on the obstacle's location as shown in Section 5.1 the following DOM hazard scenarios were identified:

1) Approach RWY 25R

2) Missed Approach RWY 07L

3) Missed Approach RWY 07C

4) Take-off RWY 07C

The following Figure 16 depicts all four scenarios.

All operations on runway 25L/07R and runway 18 were excluded from the investigation as explained in Section 5.2.

\subsubsection{DOM Step 1: Vertical Performance Analysis}

Applying the minimum climb requirements according to CS-25, we can prove compliance for scenarios 1, 2, and 3. Scenario 4 "Take-off RWY 07C" does not pass the evaluation. Table 4 shows the obstacle conflicting profiles for multi-engine aircraft (negative values indicate a flight path below the highest point of the obstacle):

Consequently, we declare all scenarios but this one as non-critical. Scenario 4 is subject to further investigation along with step 2 to 5 .

\subsubsection{DOM Step 2: Procedure Design Analysis}

In this step three separate phases will be passed:

Phase 1: Analyze the most critical departure route $e^{3}$ along EU-OPS 1.495 standards.

Results: The examination revealed that the obstacle does not penetrate the "take-off funnel", and so at least does not violate the departure clearance requirements. As explained in Section 4, this is not yet proof of compliance but a pass indicator. Further investigation leads us to:

Phase 2: Examination of the Obstacle Identification Surface (OIS) and PDG according to ICAO PANS-OPS Vol. II.

Results: This sub-step shows that the obstacle violates the OIS both laterally and vertically. As such, a PDG update is necessary to prove a further pass indicator (see Table 5).

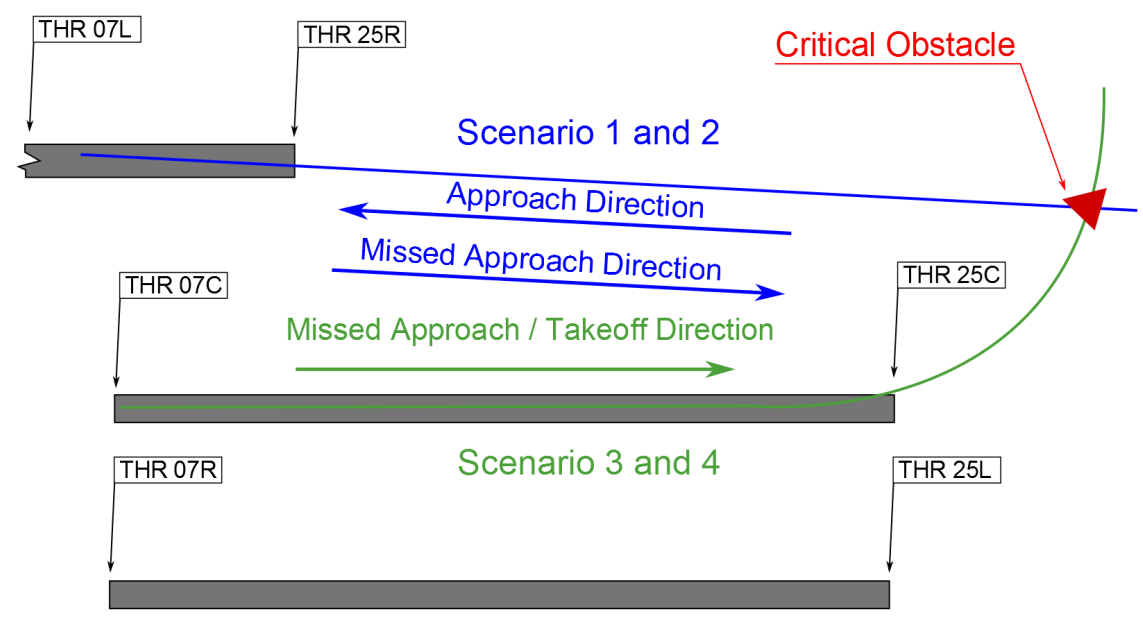

Figure 16. Identified DOM hazard scenarios—safety case FRA.

\footnotetext{
${ }^{3}$ This is the turning departure route BIBTIE 3E.
} 
Table 4. Violation altitudes scenario 4.

\begin{tabular}{ccc} 
& Scenario 4-obstacle clearance $[\mathbf{m}]$ & \\
\hline 2 engines & 3 engines & 4 engines \\
\hline-46.10 & -40.00 & -33.90 \\
\hline
\end{tabular}

Table 5. Comparison of minimum procedure design gradients.

\begin{tabular}{ccc} 
& Minimum PDG [\%] & \\
\hline As published $^{4}$ & Required \\
\hline 6.30 & 5.90 \\
\hline
\end{tabular}

Consequently, despite the identified OIS violation, the obstacle will not vertically impact the published takeoff procedure, the pass indicator is positive, leaving us with:

Phase 3: Examination of the protection area for turns according to ICAO PANS-OPS.

Results: We derive that the obstacle is located inside the protection area of BIBTI 3E. However, a calculation of the maximum allowable object height at the given location shows remaining clearance so that this pass indicator is also true.

In total, we find all three pass indicators are true without granting combined lateral and vertical compliance, so we will have to continue to step 3 :

\subsubsection{DOM Step 3: Lateral Performance Analysis}

By additionally considering the uncertainties resulting from adverse conditions and engine failure for all relevant aircraft types (e.g. A321, A340, B777F) in the TLPM, Figure 17 depicts the exemplary results of the missed approach performance analysis (OEI right prior passing the obstacle):

Results: The calculations prove that yaw motion induced by engine failure and crosswind (up to $20 \mathrm{kt}$ ) can be fully compensated by aircraft flight control. Consequently, no relevant lateral nor vertical deviations from the intended trajectory were identified for scenario 1 to 3 (partly shown in Figure 17). Scenario 4, however, showed vertical violations requiring the execution of step 4.

\subsubsection{D0M Step 4: Lateral Flyability of the Critical Trajectory}

All aircraft types able to complete the turning departure as set out with the critical trajectory are being identified. So we calculate the required climb out speed $v_{2}$ to reach the pre-set turn radius $r$ linked as follows:

$$
v=\sqrt{r \cdot g \cdot \tan (\Phi)} \geq v_{2}
$$

This delivers the following figures in Table 6.

Comparison of design speed $(v)$ with $v_{2}$ for all relevant aircraft models revealed that the required speed can only be achieved by small multi-engine jet or turboprop aircraft (e.g. Cessna C525A CJ2 or Beechcraft King Air B200GT). Even though this aircraft category is rather rare at FRA (close to pass indicator), we will have to identify the remaining risk, which is assessed in the final step 5.

\subsubsection{DOM Step 5: Vertical Performance Analysis of the Critical Trajectory}

We finally determine CG and lift-off points under the prescribed unfavorable OEI conditions to calculate the pass altitudes above the obstacle for this aircraft category, again using TLPM.

Table 7 depicts the results for the exemplary members of this aircraft category.

As a result, we prove in step 5 that the critical aircraft category can also safely overfly the critical obstacle with significant clearance according to PANS OPS (e.g. $35 \mathrm{ft} . / 10 \mathrm{~m})$. So the SA for this safety case closes with a positive result.

If, however, even step 5 fails (or any preceding step beforehand), the SA methodology allows the investigation to set out mitigation measures, such as cancelling a published route, setting stricter prerequisites to allow

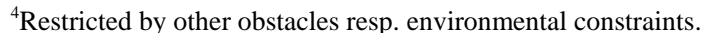




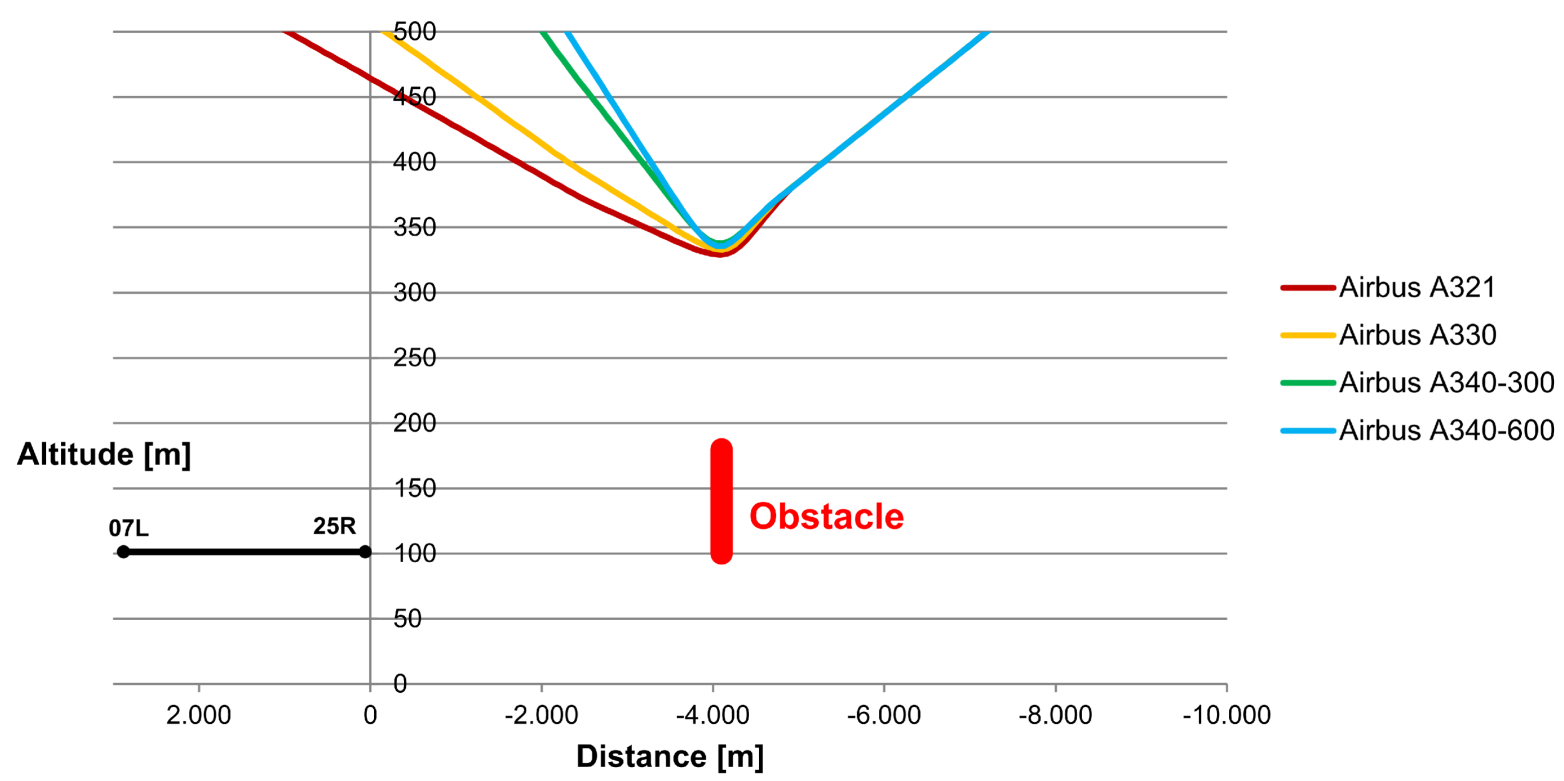

Figure 17. Missed app degraded performance analysis (scenario 2 \& 3).

Table 6. Required operational parameter configuration for the critical trajectory.

\begin{tabular}{ccc}
\hline Value & Unit & Numerical value \\
\hline Design speed $(v)$ & {$[\mathrm{m} / \mathrm{s}]$} & $\approx 54(105 \mathrm{kt})$ \\
Turn radius $(r)$ & {$[\mathrm{m}]$} & 1100 \\
Maximum bank angle $(\Phi)^{5}$ & {$\left[{ }^{\circ}\right]$} & 15 \\
Take-off safety speed $v_{2}$ & {$[\mathrm{~m} / \mathrm{s}]$} & $\leq 54(105 \mathrm{kt})$ \\
\hline
\end{tabular}

Table 7. Values for example calculation of crossing altitude.

\begin{tabular}{cccc}
\hline Aircraft & Climb gradient [\%] & Lift-off point $[\mathrm{m}]$ & Crossing altitude $[\mathrm{m}]$ \\
\hline B200GT & 42129 & 840 & 160.80 \\
C525A & 42158 & 1550 & 52.24 \\
\hline
\end{tabular}

flying that route (increased PDG or turn radius requirements to aircraft) or just generating appropriate awareness through hot spot advisories in the Aeronautical Information Publications (AIP).

\section{Conclusions-Integration Concept into ICAO Doc 9774}

Aeronautical studies are supportive means to assess the safety and regularity of operations around airports with ICAO non-compliant obstacles in place (e.g. one that violates the OLS). Doc 9774 [8], however, does not provide any guidance on how to perform such a study.

This paper presents a methodology which may contribute to standardizing the process. Dealing with both statistically representative hazard scenarios and infrequent events systematically investigated through scenario techniques, the presented model considers all potential flight situations by handling both normal and degraded performance triggered operations. In that sense, it generates a complete risk picture which has already proven useful in several certification processes with the German Ministry of Transport and the German ANS Supervisory Authority BAF. The statistical part relies on dedicated ANP value calculations, stochastic functional approximation leading to validated, procedure-specific probability density functions along any flight track allowing calculation of obstacle CR through double integration. In rare cases (often called as "PDF tails") we devel-

${ }^{5}$ Pursuant to ICAO PANS-OPS (Pt. 1-Section 2, Chapter 3, Table I-2-3-1) the maximum bank angle until $305 \mathrm{~m}$ (1000 ft.) altitude for departures is given by $\Phi=15^{\circ}$. 
oped a scenario configuration technique assuming worst case environment and aircraft performance related conditions. The resulting 3D trajectories generated through the author's take-off and landing performance model (TLPM) allows a deterministic (yes/no) collision potential determination by calculating minimum horizontal and vertical performance under unfavorable conditions for all aircraft categories operating at the investigated airport. Beyond this application case, we recall that the model reviews systematically all safety related design criteria for departure and arrival procedures. As such, its application is universe. On-going investigations run in compliance e.g. for Zurich Airport.

As such, we see strong potential for the presented methodology to become a potential candidate for an ICAO DOC 9774, Appendix 3 supplement in order to give specialists a guideline for how to adequately judge formally non-compliant obstacles for safe and regular operations at the airport. It also reveals the need for updating and extending the current ICAO's collision risk model with correct procedure and flight phase specific ANP values.

\section{Acknowledgements}

The authors thank Deutsche Flugsicherung DFS and Condor Flugdienst GmbH CFG for the provision of data for verification (NOM) and validation purposes (DOM). We also thank Fraport for the kind provision of detailed geometric data and our colleagues Christian Seiß and Martin Schlosser for their tremendous help with the extensive data analysis.

\section{References}

[1] ICAO (2009) Aerodrome Design and Operations. Annex 14, Volume 1, 5th Edition, ICAO, Montreal.

[2] ICAO (2006) Procedures for Air Navigation Services-Aircraft Operations. Doc 8168, Volume II, 5th Edition, ICAO, Montreal.

[3] EASA, Notice of Proposed Amendment (NPA) 2011-20, CS ADR DSN, Cologne, November 2011.

[4] Frauenkorn, M. (2001) FLIP_Flight Performance Using Frankfurt ILS, DFS, Langen, Germany.

[5] Thiel, C. and Fricke, H. (2010) Collision Risk on Final Approach-A Radar-Data Based Evaluation Method to Assess Safety. Proceedings of the 4th International Conference on Research in Air Transportation (ICRAT), Budapest, 1-4 June 2010, 473-480.

[6] ICAO (1980) Manual on the Use of the Collision Risk Model (CRM) for ILS Operations. Doc 9274-AN/904, ICAO, Montreal.

[7] ICAO (2004) Advanced Surface Movement Guidance and Control Systems (ASMGCS) Manual. Doc 9830, Montreal.

[8] ICAO (2001) Manual on Certification of Aerodromes. Doc 9774, Montreal.

[9] ICAO (2006) Aerodrome Design Manual (ADM), Part I Runways. Doc 9157, 3rd Edition, Montreal.

[10] EU-OPS (2008) Council Regulation (EEC) No 3922/91 on the Harmonization of Technical Requirements and Administrative Procedures in the Field of Civil Aviation. EU-OPS, Brussels.

[11] EASA (2011) Certification Specifications and Acceptable Means of Compliance for Large Aeroplanes-CS-25. Amendment 11, Cologne.

[12] FAA: Federal Aviation Regulations (FAR) Part 25-Airworthiness Standards: Transport Category Airplanes, USA.

[13] ICAO (2007) PANS ATM (Air Traffic Management). Doc 4444, 5th Edition, Montreal.

[14] EUROCONTROL (2006) Air Navigation System Safety Assessment Methodology (SAM), SAF.ET1.ST03.1000MAN-01, Edition 2.1.

[15] ICAO (2008) Performance-Based Navigation (PBN) Manual. Doc 9613-AN/937, 3rd Edition, Montreal.

[16] Thiel, C., Seiß, C., Vogel, M. and Fricke, H. (2012) Safety Monitoring of New Implemented Approach Procedures by Means of Radar Data Analysis. Proceedings of the 5th International Conference on Research in Air Transportation (ICRAT), Berkeley, 22-25 May 2012.

[17] Kaiser, M., Schultz, M. and Fricke, H. (2011) Enhanced Jet Performance Model for High Precision 4D Flight Path Prediction. Proceedings of the International Conference on Application and Theory of Automation in Command and Control Systems (ATACCS), Barcelona, 26-27 May 2011, 38-45.

[18] Condor Flight Operations Engineering, HO/E (Bölling, M., et al.), Take off and Landing Flight Performance Calculations, November 2011.

[19] DFS: FANOMOS Flight Track Data of Approaches/Departures at Frankfurt/Main Airport, May-October 2011, Langen, November 2011. 
Scientific Research Publishing (SCIRP) is one of the largest Open Access journal publishers. It is currently publishing more than 200 open access, online, peer-reviewed journals covering a wide range of academic disciplines. SCIRP serves the worldwide academic communities and contributes to the progress and application of science with its publication.

Other selected journals from SCIRP are listed as below. Submit your manuscript to us via either submit@scirp.org or Online Submission Portal.
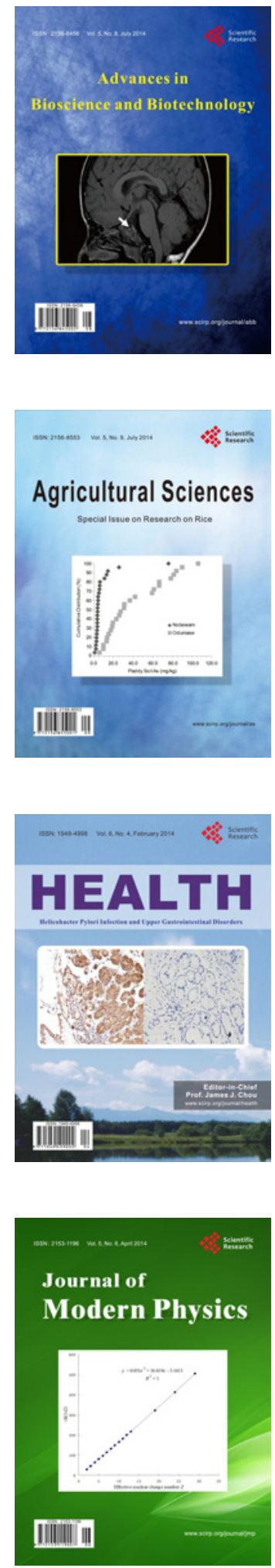
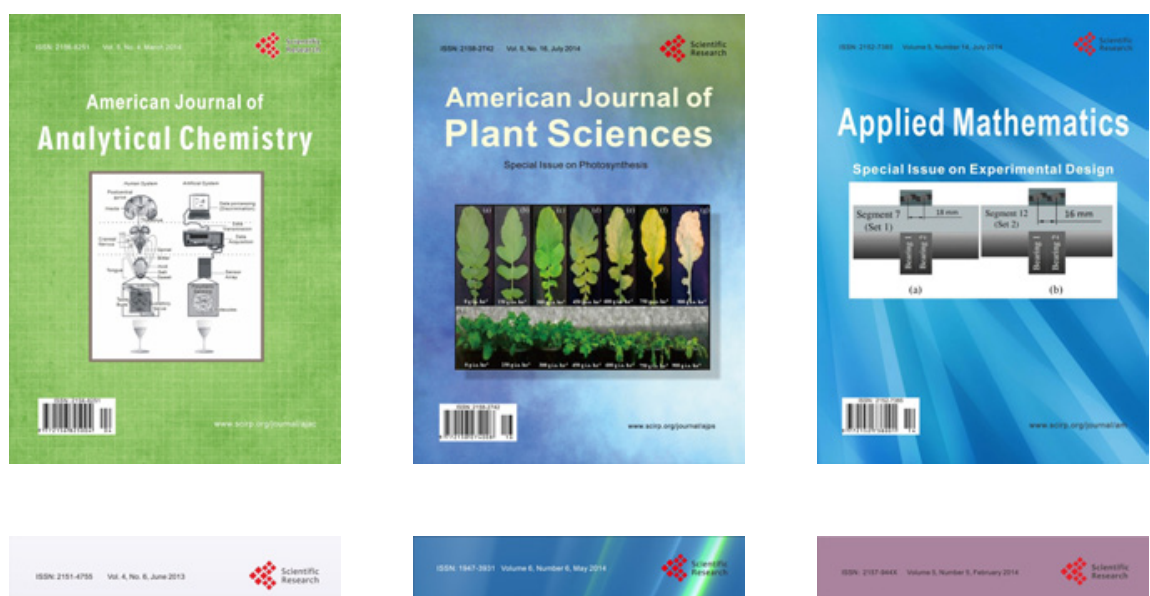

Creative Education
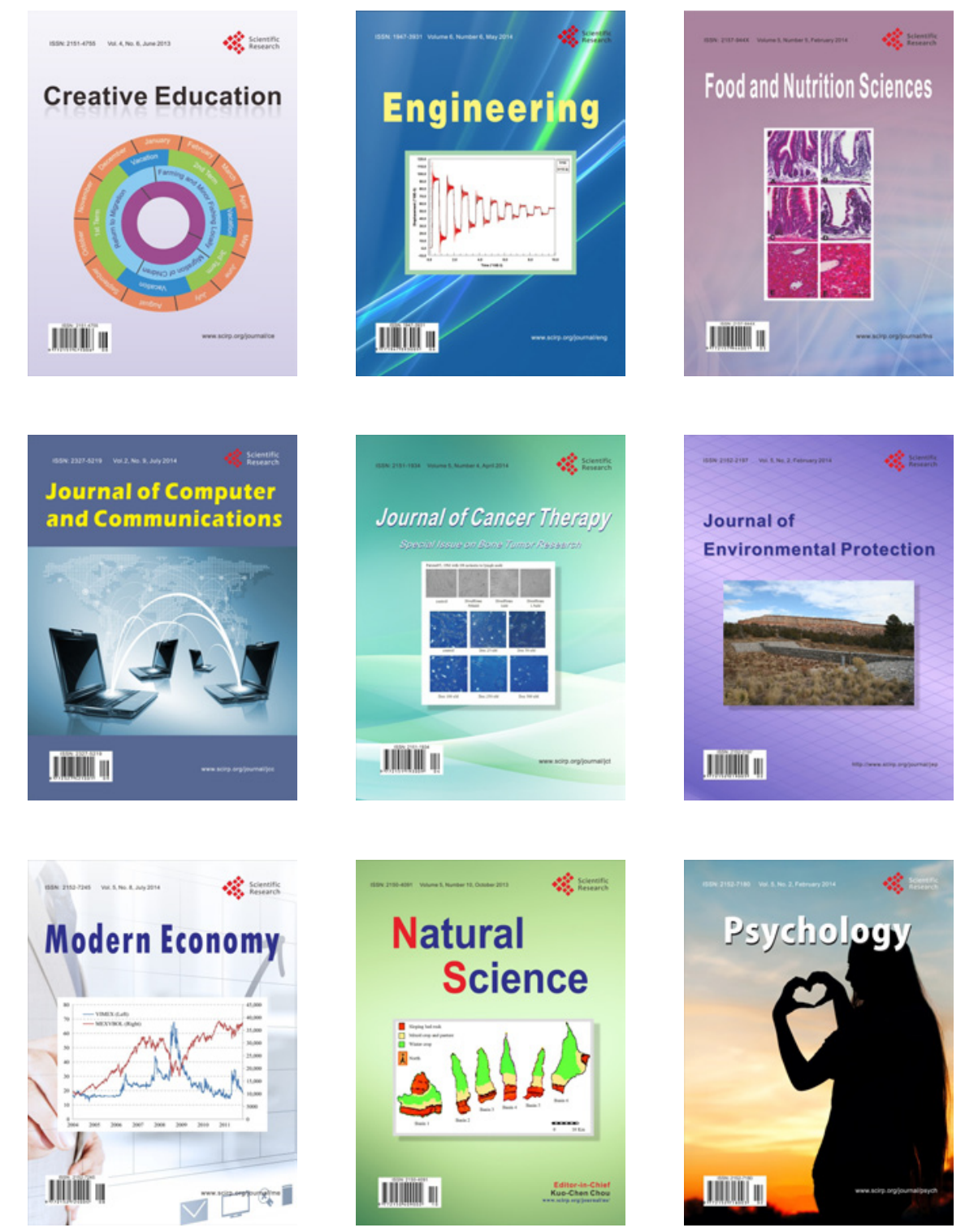